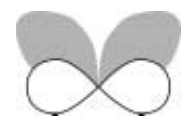

\title{
Patch occupancy of North American mammals: is patchiness in the eye of the beholder?
}

Robert K. Swihart $^{1 *}$, Todd C. Atwood ${ }^{2}$, Jacob R. Goheen ${ }^{3}$, Daniel M. Scheiman ${ }^{1}$, Karen E. Munroe $^{4}$ and Thomas M. Gehring ${ }^{5}{ }^{1}$ Department of Forestry and Natural Resources, Purdue University, West Lafayette, IN, ${ }^{2}$ Department of Forest, Wildlife, and Range Sciences, Utah State University, Logan, UT, ${ }^{3}$ Department of Biology, University of New Mexico, Albuquerque, NM, ${ }^{4}$ Department of Renewable Natural Resources, University of Arizona, Tucson, AZ and ${ }^{5}$ Department of Biology, Central Michigan University, Mt Pleasant, MI, USA

\begin{abstract}
Aim Intraspecific variation in patch occupancy often is related to physical features of a landscape, such as the amount and distribution of habitat. However, communities occupying patchy environments typically exhibit non-random distributions in which local assemblages of species-poor patches are nested subsets of assemblages occupying more species-rich patches. Nestedness of local communities implies interspecific differences in sensitivity to patchiness. Several hypotheses have been proposed to explain interspecific variation in responses to patchiness within a community, including differences in (1) colonization ability, (2) extinction proneness, (3) tolerance to disturbance, (4) sociality and (5) level of adaptation to prevailing environmental conditions. We used data on North American mammals to compare the performance of these 'ecological' hypotheses and the 'physical landscape' hypothesis. We then compared the best of these models against models that scaled landscape structure to ecologically relevant attributes of individual species.
\end{abstract}

Location North America.

Methods We analysed data on prevalence (i.e. proportion of patches occupied in a network of patches) and occupancy for 137 species of non-volant mammals and twenty networks consisting of four to seventy-five patches. Insular and terrestrial networks exhibited significantly different mean levels of prevalence and occupancy and thus were analysed separately. Indicator variables at ordinal and family levels were included in models to correct for effects caused by phylogeny. Akaike's information criterion was used in conjunction with ordinary least squares and logistic regression to compare hypotheses.

Results A patch network's physical structure, indexed using patch area and isolation, received the greatest support among models predicting the prevalence of species on insular networks. Niche breadth (diet and habitat) received the greatest support for predicting prevalence of species occupying terrestrial networks. For both insular and terrestrial systems, physical features (patch area and isolation) received greater support than any of the ecological hypotheses for predicting species occupancy of individual patches. For terrestrial systems, scaling patch area by its suitability to a focal species and by individual area requirements of the species, and scaling patch isolation by speciesspecific dispersal ability and niche breadth, resulted in models of patch occupancy that were superior to models relying solely on physical landscape features. For all selected models, unexplained levels of variation were high.

\footnotetext{
"Correspondence: Robert K. Swihart, Department of Forestry and Natural Resources, Purdue University, West Lafayette, IN 47907-2033, USA.

E-mail: rswihart@fnr.purdue.edu
} 
Main conclusions Stochasticity dominated the systems we studied, indicating that random events are probably quite important in shaping local communities. With respect to deterministic factors, our results suggest that forces affecting species prevalence and occupancy may differ between insular and terrestrial systems. Physical features of insular systems appeared to swamp ecological differences among species in determining prevalence and occupancy, whereas species with broad niches were disproportionately represented in terrestrial networks. We hypothesize that differential extinction over long time periods in highly variable networks has driven nestedness of mammalian communities on islands, whereas differential colonization over shorter time-scales in more homogeneous networks probably governed the local structure of terrestrial communities. Our results also demonstrate that integration of a species' ecological traits with physical features of a patch network is superior to reliance on either factor separately when attempting to predict the species' probability of patch occupancy in terrestrial systems.

\section{Keywords}

Colonization, ecological scaling, extinction, habitat fragmentation, islands, mountaintops, nested subsets, niche breadth, stochasticity, woodlots.

\section{INTRODUCTION}

Most landscapes are patchy, inasmuch as localities vary in terms of their suitability as habitat for a species. The ecological literature is replete with examples documenting individual and population-level responses to resource heterogeneity (e.g. McGlynn et al., 2002). When heterogeneity is extreme, resource patches occur as discrete entities surrounded by areas that are unsuitable for long-term persistence. Examples of such extreme patchiness include insular systems, or networks of remnant terrestrial habitat patches embedded in human-dominated landscapes of agricultural or urban areas. Field studies have documented numerous patchy landscapes in which species differ, sometimes dramatically, in their responses to resource heterogeneity (Andrén, 1994; Laurance, 1995; Bender et al., 1998; Knutson et al., 1999). These interspecific differences can lead to a structured gradient of local community assemblages across a landscape, as the species most sensitive to patchiness disappear from all but the largest or most well-connected patches and the least sensitive species occur ubiquitously. Such a non-random ordering of local assemblages has been termed nestedness (Patterson, 1984; Patterson \& Atmar, 1986).

Nestedness is a common feature of metacommunities and tends to occur when (1) patches in a network are comparable in terms of structural and habitat features, (2) species share a similar biogeographical history, and (3) species form an ordered hierarchy in terms of ecological factors that influence incidence (Patterson \& Brown, 1991; Wright et al., 1998). In this paper, we examine hypotheses to explain the formation of nested assemblages of North American mammals. We then evaluate integrated hypotheses for the formation of nestedness that permit interspecific differences in perceptions of patchiness to be combined with physical attributes of a patchy system.

Phenomenological models of patchy systems (MacArthur \& Wilson, 1967; Levins, 1969) have focused on colonization and extinction dynamics of local populations. The temporal scale over which populations are tracked can have important implications for interpreting dynamics. For long-lived species with low turnover rates, long time-lags following the formation of a patchy network may be needed to approach equilibrial conditions of occupancy (Tilman et al., 1994; Nagelkerke et al., 2002). If observations of such systems occur after shorter lag periods, occupancy patterns may be inflated above equilibrial levels because records of occurrence will be made for local populations doomed to eventual extinction, thus yielding overly optimistic assessments of a species' likelihood of persistence in the network (Ter Braak et al., 1998; Clinchy et al., 2002). In this paper, we explore the effect of time since formation of patch networks on species prevalence and occupancy.

The original phenomenological models and their derivatives predict that a species' sensitivity to extreme resource patchiness generally is related to its ability to persist locally and to recolonize patches by moving across a landscape (Hanski, 1998; Etienne \& Heesterbeek, 2001; Vos et al., 2001). Morphological, ecological and behavioural attributes should thus interact with abiotic landscape attributes to determine the viability of populations inhabiting patchy environments (Hanski \& Ovaskainen, 2000; Vos et al., 2001), which in turn influences the structure of communities (Belant \& Van Stappen, 2002; Swihart et al., 2003). Below, we provide an overview of hypotheses linking species attributes with their sensitivities to extreme resource patchiness. We then compare the hypotheses using presenceabsence data on 137 species of mammals collected from twenty patch networks in North America. Finally, we ask whether our understanding of variation in responses to resource patchiness can be improved by scaling the physical features of a landscape with ecologically relevant attributes affecting a species' colonization and extinction rates.

The models that we have tested do not comprise an exhaustive list, but instead were chosen based on prior 
theoretical and empirical work suggesting their importance (Anderson et al., 2000). In describing the hypotheses, we begin with a 'null' model, proceed to a model focusing exclusively on the physical environment, and then outline a series of ecological models that highlight particular species attributes. We recognize that partial overlap is possible in some of the ecological models but believe that they differ sufficiently to warrant separate consideration.

\section{Null model: phylogenetic effects}

Variation in responses to patchiness may in part be due to evolutionary constraints imposed by phylogeny. Closely related species are likely to be more similar phenotypically and in terms of ecology and life history than distantly related species, as a consequence of niche conservatism, phylogenetic time-lags, and shared constraints on adaptive responses (Harvey \& Pagel, 1991). Thus, consideration of the variation attributable to phylogeny is a necessary condition for examining factors that explain variation independent of these phylogenetic effects. Our null model predicts that closely related taxa should exhibit more similar patterns of occupancy and prevalence than more distantly related taxa. Thus, we used phylogenetic effects as a baseline from which models of physical and ecological factors could be compared.

\section{Physical model: area and isolation}

Landscape ecologists have focused considerable effort on describing the complex physical structure of landscapes, with a goal of summarizing the patchiness embodied by an arrangement of spatial elements into statistics that have ecological significance (e.g. Gustafson \& Parker, 1992; Schumaker, 1996; Tischendorf \& Fahrig, 2000a,b; Urban \& Keitt, 2001). Numerous empirical studies have documented the importance of two attributes, patch area and patch isolation, as determinants of species occupancy (e.g. Dunning et al., 1995; Rosenzweig, 1995; Hanski, 1998). Support for the importance of patch area is not altogether surprising, because extinction of local populations can be influenced dramatically by stochasticity. This is especially true when populations are small (Berger, 1990). In addition, immigration to patches often can be modelled as a distancedependent phenomenon (Hanski, 1998). The physical model thus predicts that occupancy and prevalence should be positively related to patch area and negatively related to patch isolation. Additionally, increased variation in the range of patch area and isolation within a network should result in increased nestedness of communities compared with other networks (Wright et al., 1998).

\section{Ecological model I: proximity to range edge}

A species' abundance often declines spatially from the core to the periphery of its range (Brown, 1984; Brown et al., 1995). This pattern emerges because core areas of a range presumably contain more suitable habitat in terms of niche requirements and more suitable abiotic conditions for the species' survival, resulting in lower turnover rates (Enquist et al., 1995; Brown et al., 1996; Pulliam, 2000). The rangeboundary hypothesis thus predicts that prevalence and occupancy levels will be lower for a species near the edge of its geographical range.

\section{Ecological model 2: colonization ability}

Species perceptions of resource patchiness can differ in at least two fundamental ways, depending on variation in responses to (1) the amount and (2) the distribution of habitable sites. The colonization model focuses on the latter issue and hypothesizes that the distance a species can disperse is a critical determinant of its ability to colonize other patches. Dispersal distance is related to home-range size (Bowman et al., 2002), which in turn is responsive to energetic and morphological constraints on body size, locomotion (e.g. quadrupedal, gliding, volant), or substrate use (e.g. aquatic, semi-aquatic, terrestrial) (Eisenberg, 1981; Kelt \& Van Vuren, 1999, 2001; Lynam \& Billick, 1999). The colonization model thus predicts greater prevalence and occupancy levels for species with well-developed dispersal capabilities.

\section{Ecological model 3: extinction proneness}

The extinction model focuses on interspecific differences in responses to the area available for occupancy by a population. For a given patch area, a greater population density is associated with a reduced risk of local extinction due to stochastic effects (Berger, 1990). Conversely, larger-bodied species are thought to exhibit greater population stability because they are better able to withstand environmental bottlenecks (see Belovsky, 1987; Goodman, 1987). The extinction model thus predicts that prevalence and occupancy should increase with population density and body size.

\section{Ecological model 4: niche breadth}

If local patches exhibit variation in resource composition, species capable of exploiting multiple resource types are less likely to be absent from any single patch. Conversely, specialists probably will be absent from patches lacking the habitat (or prey) upon which they depend. In terrestrial systems, human disturbances often result in reversion of portions of the landscape to earlier successional stages, or creation of a structurally simplified matrix separating patches of native habitat. A generalist is probably more capable than a specialist of using the human-created matrix as an alternative habitat and extracting some resources from it (Andrén, 1994; Laurance, 1995; Sarre et al., 1995; Gascon et al., 1999; Bentley et al., 2000; Laurance et al., 2002). This should be especially true of species that use early successional habitats, as evolution in these habitats favours species with larger dispersal rates or dispersal ranges (Comins et al., 1980; Hanski, 1999). Finally, species that are dietary generalists should be less negatively affected by resource patchiness resulting from habitat fragmentation than dietary specialists, because they will be less susceptible 
to increased variation in the availability of native food resulting from habitat loss (Swihart \& Nupp, 1998; Swihart et al., 2001). The niche-breadth hypothesis thus predicts that a species with the ability to use a broad array of habitats and food types should be less adversely affected by resource patchiness than a more stenotypic species.

\section{Ecological model 5: degree of sociality}

Sociality or gregariousness may impose limits on colonization rates or on the size of a patch that can support a viable population, because social groups rather than solitary individuals are instrumental to population growth (Smith \& Peacock, 1990; Ray et al., 1991; Tyutyunov et al., 1996; Minchinton, 1997; Courchamp et al., 1999; Lawes et al., 2000). Wolff (1999) hypothesized that behavioural attributes, including sociality, may be important determinants of a species' colonization ability in fragmented landscapes. The sociality hypothesis thus predicts that highly social species should be negatively affected by habitat fragmentation, due principally to area effects that limit the carrying capacity of a patch. The result, then, is a lower threshold on sizes of patches that can be colonized.

\section{Joint models: ecological scaling of patchiness}

The importance of physical features of patch networks to a population's persistence has theoretical (Levin, 1992; Durrett \& Levin, 1994) and empirical (Debinski \& Holt, 2000) support. Moreover, it seems intuitive that the scale at which resource patchiness operates is dependent upon species perceptions and responses to a patch network. Ecologically scaled landscape indices (ESLIs) (Vos et al., 2001) combine physical features of a patch network with ecologically relevant characteristics of species that reflect the scales at which they respond to that network. In this paper, we evaluated the performance of the ESLIs of Vos et al. (2001), which combine physical metrics with individual area requirements and dispersal ability. We also evaluated ESLIs that were modified to incorporate the effects of niche breadth and habitat suitability, as described below.

\section{METHODS}

We collected data on prevalence and occupancy of nonvolant mammals from twenty patch networks across North America (Table 1). For each species, we recorded occupancy

Table I Summary of patch networks included in the analysis of prevalence and occupancy for North American mammals. Min, minimum; Max, maximum

\begin{tabular}{|c|c|c|c|c|c|}
\hline Location & $\begin{array}{l}\text { Number } \\
\text { of patches }\end{array}$ & $\begin{array}{l}\text { Median patch } \\
\text { area }\left(\mathrm{km}^{2}\right)\end{array}$ & $\begin{array}{l}\text { Min : } \max \\
\text { area }\end{array}$ & $\begin{array}{l}\text { Median nearest } \\
\text { neighbour }(\mathrm{km})\end{array}$ & $\begin{array}{l}\text { Min : max } \\
\text { nearest neighbour }\end{array}$ \\
\hline \multicolumn{6}{|l|}{ Terrestrial networks } \\
\hline Great Basin mountaintops ${ }^{1}$ & 19 & 384 & 0.01019 & 15 & 0.050 \\
\hline Great Basin mountaintops ${ }^{2}$ & 19 & 384 & 0.01019 & 15 & 0.050 \\
\hline Great Basin mountaintops ${ }^{3}$ & 23 & 571 & 0.00781 & 9 & $<0.0000$ \\
\hline Southern Rocky mountains ${ }^{4}$ & 26 & 2250 & 0.00160 & 29 & $<0.0000$ \\
\hline Southern Rocky mountains ${ }^{5}$ & 27 & 107 & 0.00090 & 17 & $<0.0000$ \\
\hline Illinois woodlots ${ }^{6}$ & 10 & 0.24 & 0.00300 & 1.54 & 0.0011 \\
\hline Iowa woodlots ${ }^{7}$ & 11 & 0.0004 & 0.14554 & 0.64 & $<0.0000$ \\
\hline Indiana woodlots ${ }^{8}$ & 37 & 0.02 & 0.00009 & 0.11 & 0.0141 \\
\hline Indiana woodlots 9 & 5 & 0.08 & 0.09612 & 0.21 & 0.3296 \\
\hline Wisconsin woodlots ${ }^{10}$ & 22 & 0.05 & 0.01000 & 1.6 & 0.2000 \\
\hline Indiana woodlots $^{11}$ & 45 & 0.05 & 0.00036 & 0.11 & 0.0014 \\
\hline \multicolumn{6}{|l|}{ Insular networks } \\
\hline Southern California coast ${ }^{12}$ & 8 & 105 & 0.01054 & 42 & 0.2841 \\
\hline St Lawrence River, New York $^{13}$ & 20 & 0.03 & 0.00007 & 0.9 & 0.0020 \\
\hline Western Mexico coast ${ }^{14}$ & 4 & 70 & 0.08333 & 5.5 & 0.1875 \\
\hline \multirow[t]{2}{*}{ Gulf of Maine ${ }^{15}$} & 24 & 0.67 & 0.00001 & 1.2 & 0.0073 \\
\hline & $8 *$ & 27.3 & 0.04566 & 1.6 & 0.0125 \\
\hline Virginia coast ${ }^{16}$ & 9 & 5.08 & 0.01320 & 1 & 0.1587 \\
\hline Lake Michigan $^{17}$ & 14 & 1.02 & 0.00152 & 3 & 0.0089 \\
\hline Alaska coast ${ }^{18}$ & 24 & 477 & 0.00175 & 6 & 0.0296 \\
\hline Sea of Cortez, Mexico ${ }^{19}$ & 20 & 20 & 0.00033 & 4 & 0.0417 \\
\hline British Columbia coast ${ }^{20}$ & 75 & 26 & 0.00002 & 2 & 0.0026 \\
\hline
\end{tabular}

${ }^{1}$ McDonald \& Brown (1992); ${ }^{2}$ Grayson \& Livingston (1993); ${ }^{3}$ Brown (1978); Brown \& Gibson (1983); ${ }^{4}$ Patterson \& Atmar (1986); ${ }^{5}$ Lomolino et al. (1989); ${ }^{6}$ Rosenblatt et al. (1999); ${ }^{7}$ Gottfried (1979); ${ }^{8} \mathrm{Nupp} \&$ Swihart (2000); ${ }^{9} \mathrm{Nupp}$ \& Swihart (unpublished data); ${ }^{10} \mathrm{Matthiae} \&$ Stearns (1981); ${ }^{11}$ Gehring (2000); ${ }^{12}$ von Bloeker (1967); ${ }^{13}$ Lomolino (1986); ${ }^{14}$ Wilson (1991); ${ }^{15}$ Crowell (1986); ${ }^{16}$ Dueser \& Brown (1980); ${ }^{17}$ Hatt et al. (1948); ${ }^{18}$ Conroy et al. (1999); ${ }^{19}$ Lawlor (1983, 1986); ${ }^{20}$ McCabe \& Cowan (1945); Foster (1965); Redfield (1976); Lawlor (1986).

*Occurrence data were provided for two sets of species by Crowell (1986), with some species sampled at all twenty-four islands and others at only the eight largest islands. 
as a binary variable and prevalence as the proportion of patches in a network that were occupied. Seven of the data sets were used by Wright et al. (1998) in their analysis of nestedness. We conducted a literature search to augment these with more recent studies and with networks not included in their analysis. Eleven studies were conducted on patch networks in which the intervening matrix consisted of terrestrial vegetation. The remaining studies were of island networks.

\section{Physical features of networks}

For each patch in a network, we recorded the patch area $\left(\mathrm{km}^{2}\right)$ and distance to its nearest neighbouring patch $(\mathrm{km})$. Summary statistics for each network included median patch area, median distance to nearest neighbour, and the ratios minimum patch area : maximum patch area as well as minimum nearest neighbour distance : maximum nearest neighbour distance. We also recorded the types of habitat occurring on each patch, or for an entire network if patchspecific information was lacking.

\section{Derivation of ecological descriptor variables}

For each species considered in the studies from Table 1, ecological attributes were summarized from a variety of literature sources (Appendix). Whenever possible, sources were used from regions in close proximity to patch networks. When multiple sources were available for an attribute, weighted averages were computed based on sample sizes. If data were unavailable for a species, values were imputed from the species most closely related to it, which probably exaggerate phylogenetic effects.

\section{Proximity to range edge}

Data for testing the range-edge hypothesis were generated from a geographical information system. We digitized range maps from Hall (1981) for each species. A digitized map of the geographical localities of the patch networks was then superimposed on each species range map. For each species recorded in a patch network, we computed the distance from the centroid of the species' range to (1) the patch network and (2) the range edge closest to the focal network. The ratio of these two measures was used to quantify proximity to a range boundary; a value of zero characterized a network falling near the centre of the species' range, whereas a value of 1 characterized a network occurring on the edge of the species' range.

\section{Colonization ability}

Two types of variables were used in conjunction with the colonization model. Indicator variables were used to designate six categories related to mode of locomotion: fossorial, gliding, semi-fossorial, semi-arboreal, semi-aquatic and terrestrial. Additionally, data on maximum dispersal distance $\left(d_{\max }\right.$ in $\left.\mathrm{km}\right)$ were available for forty-four of the 137 species in our study (Sutherland et al., 2000). These data were used to establish a nonlinear predictive equation relating $d_{\max }$ to published and unpublished data on home-range area (HR in $\mathrm{km}^{2}$, Appendix). The model producing the best fit was

$$
d_{\max }=22.5 \mathrm{HR}^{0.29}
$$

$\left(r^{2}=0.45\right)$. Home-range areas for the remaining species were then used in the regression model to compute predicted values of $d_{\max }$ for species lacking observed values of $d_{\max }$.

\section{Extinction proneness}

Body size was indexed using data on adult body mass $(\mathrm{kg})$, averaged between the sexes. Local population density (individuals $\mathrm{km}^{-2}$ ) was taken from studies reporting density directly, or from studies for which estimates could be derived from data on individuals captured and area sampled.

\section{Niche breadth}

Individuals of widespread species should have broader tolerances for environmental conditions than individuals of restricted species (Brown, 1995). In one sense this may seem obvious, because widespread species encounter a broader array of environmental conditions across their ranges. However, a species' niche breadth may reflect geographical differences among populations, with relatively little variation in niche breadth evident within populations. Thus, it is important to assess the degree to which niche breadth, measured across a species' geographical range, corresponds to a single population's ability to cope with habitat alteration. We estimated niche breadth along two dimensions, habitat and diet. Although comparison of resource use with resource availability is desirable when assessing niche breadth (e.g. Manly et al., 1993), data on availability seldom are reported. Consequently, we relied only on used resources in our computations.

Each species was assigned a dietary breadth rating on a scale of $1-5$. Species receiving a rank of 1 were considered extreme specialists that feed only on one or a few taxa within a dietary class. Species receiving a rank of 2 were specialists, restricted to a single dietary class but feeding on several taxa within that class. Species assigned a rank of 3 were facultative specialists that usually feed on items from a single dietary class but rarely would feed on other dietary classes. Species assigned a rank of 4 were generalists and differed from facultative specialists in commonly feeding on dietary classes other than the predominant class. Species receiving a rank of 5 were considered extreme generalists that feed opportunistically on foods of more than one dietary class.

In a similar fashion, each species was assigned a habitat breadth score on a scale of $1-15$, with 15 representing the greatest variety of habitats used. The fifteen habitat classes considered in assigning scores for habitat breadth were temperate deciduous forest, temperate coniferous forest, temperate mixed deciduous-coniferous forest, temperate grassland, temperate savanna, temperate shrub-scrub, wetlands, Mediterranean shrub, Mediterranean savanna, xeric shrub-scrub, xeric desert, taiga, tundra, tropical moist broadleaf forest, and tropical dry broadleaf forest (Ricketts et al., 1999). 
A single niche-breadth variable with a mean of zero and a standard deviation of 1 was derived as

$$
Z_{\mathrm{H}+\mathrm{D}}=\frac{Z_{\mathrm{H}}+Z_{\mathrm{D}}}{s_{\left(Z_{\mathrm{H}}+Z_{\mathrm{D}}\right)}},
$$

where $Z_{\mathrm{H}}$ and $Z_{\mathrm{D}}$ are standardized (zero mean, unit variance) variables for the dietary and habitat breadth scores, respectively, and the denominator is the standard deviation of the sum of these variables.

In an attempt to provide a crude summary of niche breadth, we also categorized each species in terms of (1) whether it was omnivorous and (2) whether its habitat requirements matched the availability of a particular patch (or patch network). The former variable was a binary indicator variable, whereas the latter variable, labelled $h$, was estimated on an interval scale $0-1$, with 0 representing the absence of suitable habitat and 1 representing ample suitable habitat. For networks lacking information regarding the habitat of specific patches, a single value of $h$ was used for all patches in the network. These two variables, together with $Z_{\mathrm{H}+\mathrm{D}}$, formed the basis for assessing the niche-breadth model.

\section{Degree of sociality}

Sociality was indexed on a scale of $0-4$. Species received a rating of 0 if they were asocial and exhibited no male care of offspring. Species were assigned a rating of 1 if they exhibited rudimentary sociality (e.g. huddling, overlap of home ranges) but no male care. Species received a rating of 2 if they formed matrilineal groups or other kin groups but no male care. A rating of 3 was assigned to monogamous species in which males provided some care of offspring. Finally, a rating of 4 was assigned to species consisting of communal groups and in which cooperative foraging and offspring care had been documented. Sociality clearly is a phenotypically flexible trait (Swihart, 1992; Revilla \& Palomares, 2002); thus, when multiple sources reported different social structures, we used the study that was closest to the focal network(s). Otherwise, ratings from the different studies were averaged.

\section{Ecological scaling of patchiness}

We used two methods to scale patch networks according to ecological attributes of species. Metapopulation theory provided the basis for both approaches. The incidence of a species in a patch, $P$, is given by $P=C /(C+E)$, where $C$ and $E$ are colonization and extinction rates, respectively (Hanski, 1994). The viability of a metapopulation is determined by the ratio $C / E$, which for many species are isolation-dependent $(C)$ and area-dependent $(E)$ processes; thus, ecological scaling of patchiness addressed these two critical parameters.

The first method was developed by Vos et al. (2001). They linked landscape structural features with ecologically relevant measures of a species' sensitivity to isolation and area effects by defining the carrying capacity (2) and connectivity (3) of patch $i$ :

$$
\operatorname{ESLI}_{K_{i}}=\frac{A_{i}}{\mathrm{IAR}_{i}}
$$

$$
\operatorname{ESLI}_{C_{i}}=\sum_{\text {all } j \neq i}^{n} A_{j} \mathrm{e}^{-\alpha d_{i j}} .
$$

In equation $2, A_{i}$ is the area of patch $i$ and $\mathrm{IAR}_{i}$ is the area in patch $i$ required by one reproductive unit of a species. In equation $3, d_{i j}$ is the distance between focal patch $i$ and another patch $j$, and $1 / \alpha$ is the mean dispersal distance for the species. Limitations on the data available to us necessitated the following changes to the indices of Vos et al. (2001). We substituted local population density, $D$, for $\mathrm{IAR}_{i}^{-1}$ when calculating $\mathrm{ESLI}_{K_{i}}$. For $\mathrm{ESLI}_{C_{i}}$ we restricted our attention to the nearest neighbouring patch rather than all other patches in the network. Also, because we had more data on maximum dispersal distances than on mean (or median) distances, we calculated the dispersal parameter such that it occurred at the 0.999 quantile of the negative exponential distribution; i.e. $\alpha=-\ln (0.001) / d_{\max }$. We used observed values of $d_{\max }$ when available, and values predicted from equation 1 for all other species. An alternative approach to calculating the dispersal parameter using the median $\left(d_{\text {med }}\right)$ would have resulted in $\alpha=-\ln (0.5) / d_{\text {med }}$. For the thirteen species of mammals in our data set with both median and maximum dispersal distances, the values of $\alpha$ were highly correlated $(r=0.97, P<0.001)$ and comparable in magnitude (paired $t=0.58, P=0.57$ ).

The ecological scaling of patches developed by Vos et al. (2001) does not explicitly address variation in quality of patches or factors unrelated to distance that could affect connectivity. Our second method of scaling patchiness addressed these issues by defining a modified carrying capacity (4) and connectivity (5) for patch $i$ :

$$
\begin{gathered}
\operatorname{ESLI}_{K_{i}}^{*}=b_{i} A_{i} D, \\
\operatorname{ESLI}_{C_{i}}^{*}=A_{j} \mathrm{e}^{-a^{*} d_{i j}} .
\end{gathered}
$$

Patch carrying capacity was modified to include a variable, $b_{i}$, representing the quality of the patch in terms of meeting the habitat needs of the focal species. The variable $h_{i}$ was scaled from 0 to 1 , such that carrying capacity was 0 if the patch contained no suitable habitat for the focal species, and equalled the original index of Vos et al. (2001) when $h_{i}=1$. Patch connectivity was modified via the dispersal parameter. We reasoned that estimates of dispersal distance might be improved by considering the ease with which individuals of a species might traverse or extract resources from the matrix separating patches. For terrestrial networks of patches, species with broad niches probably find areas between patches less hostile than species with narrow, specialized resource requirements. For terrestrial patch networks, we therefore modified equation 1 to include a linear relationship with standardized niche breadth, $\mathrm{NB}_{z}$, yielding

$$
d_{\max }^{*}=20.86 \mathrm{HR}^{0.31}+\left(8.48 \mathrm{NB}_{z}-1.27\right)
$$

with $r^{2}=0.49$. As equation 6 conceivably could yield negative values of $d_{\max }^{*}$ for specialists with small home ranges, we used 1 home-range diameter as a minimum $d_{\max }^{*}$ value. For insular systems, isolation effects are probably more 
pronounced for species with limited abilities for travelling through water or over ice. For island studies, we estimated $d_{\text {max }}^{*}$ using equation 1 for semi-aquatic mammals and mammals with a terrestrial mode of locomotion occupying systems where travelling across ice was a possibility. For all other cases, maximum dispersal distance was the minimum of $d_{\max }^{*}$ or island diameter (estimated by assuming a circular shape).

\section{Statistical analysis}

The forces structuring insular and terrestrial networks may be quite different, in part because of the different timescales over which patchiness typically operates in the two situations (Hubbell, 2001). In addition, true islands have discrete boundaries and are surrounded by uninhabitable matrix, whereas edges of terrestrial patches often are less distinct and the intervening matrix can exhibit varying levels of habitability. Because of these differences, we tested our hypotheses separately for insular and terrestrial networks. Multiple linear regression was used with data on prevalence, and multiple logistic regression was used with data on patch occupancy. Before analyses, logarithmic transformations were performed on patch area, nearestneighbour distance, body size, dispersal distance, population density, and ESLIs. Prevalence data were subjected to a variance-stabilizing arcsine-square root transformation (Draper \& Smith, 1998). Methods for comparing models are described below.

To remove covariation in responses that were due to phylogenetic similarity, we constructed a set of nineteen phylogenetic indicator variables, five for ordinal contrasts and fourteen for contrasts of families within orders (Harvey \& Pagel, 1991, p. 130). For analysis of prevalence, we conducted a multiple regression against the phylogenetic variables to remove phylogenetic effects. Subsequently, regression models were constructed using the residuals from the phylogeny regression to test hypotheses. For analysis of occupancy, we included phylogenetic indicator variables in all logistic models. We also included indicator variables for patch networks to remove variability caused by differences among networks in the number of patches.

Akaike's information criterion (AIC) links the information lost because of reliance on an approximating model to the method of maximum likelihood (Burnham \& Anderson, 1998). The model with a minimum AIC among a candidate set of models is judged as the 'best' model, in the sense of maximizing model likelihood in a parsimonious manner. We compared our hypotheses using AIC corrected for sample size, $\mathrm{AIC}_{\mathrm{c}}$ (Burnham \& Anderson, 1998; Anderson et al., 2000). To easily assess evidence for the alternative models, we rescaled the $\mathrm{AIC}_{\mathrm{c}}$ values by subtracting from each the minimum $\mathrm{AIC}_{\mathrm{c}}$. The resulting values, $\Delta_{i}$, were scaled such that $\Delta_{i}=0$ for the model with minimum $\mathrm{AIC}_{\mathrm{c}}$. Rules of thumb provided by Burnham \& Anderson (1998, p. 123) suggest that models with $\Delta_{i} \leq 7$ probably will contain the actual best model from a candidate set in $95 \%$ of all samples. For models with $\Delta_{i}>10$, this is strong evidence that the model is not competitive as the best model. Results for all models were presented following the suggestions of Anderson \& Burnham (2002). After the models with greatest support had been selected using $\mathrm{AIC}_{c}$, we estimated their parameters and goodness-of-fit.

\section{RESULTS}

Terrestrial and insular networks did not differ in average median area or nearest-neighbour distance $(P>0.35$ for both $t$ tests). Mean $( \pm \mathrm{SE})$ ratios of minimum and maximum patch areas were smaller for insular systems $(0.005 \pm 0.001)$ than for terrestrial networks $(0.012 \pm 0.002) \quad(t=2.88$, d.f. $=264, P=0.004)$. Similarly, mean ratios of minimum and maximum nearest-neighbour distances were smaller for insular systems $(0.41 \pm 0.03)$ than for terrestrial networks $(0.66 \pm 0.06) \quad(t=3.80$, d.f. $=248, P<0.001)$. Within terrestrial networks, montane networks and networks of woodland remnants differed significantly $(P \leq 0.002$ for all tests), with montane networks exhibiting larger patches, greater nearest-neighbour distances, and greater variation in patch area and isolation.

\section{Species prevalence in patch networks}

Species occupying terrestrial networks exhibited a greater mean level of prevalence $(0.40 \pm 0.02)$ than species occupying insular systems $(0.27 \pm 0.02)(t=3.85$, d.f. $=332$, $P<0.001)$. Likewise, mean prevalence of species occupying forest remnants in agricultural landscapes $(0.48 \pm 0.04)$ was greater than for species in montane regions $(0.35 \pm 0.03)$ $(t=2.37$, d.f. $=104, P=0.02)$.

For insular systems, ordinal and familial effects accounted for $14.8 \%$ of the variation in prevalence $(F=1.46$, d.f. $=17,142, P=0.12$ ). For terrestrial systems, $17.8 \%$ of the variation in prevalence $(F=2.47$, d.f. $=14,174$, $P=0.003$ ) was explained by phylogeny at the order and family level. Subsequent model comparisons were made using residuals from these regressions.

Comparison of the ecological models with the physical model produced contrasting results for the two systems. For insular systems, the model receiving the greatest support (i.e. lowest $\mathrm{AIC}_{\mathrm{c}}$ ) was the physical model, with ecological models highly unlikely to be the best model in the set (Table 2). For terrestrial networks, the niche-breadth model received the greatest support, with a modest likelihood that range edge also could be the best model. The physical model was highly unlikely to be the best model for terrestrial networks (Table 2).

The fitted model for physical features of insular systems accounted for $6.7 \%$ of the residual variation in prevalence $(F=2.79$, d.f. $=4,159, P=0.03)$, after removing phylogenetic effects. Of the four explanatory variables included in the fitted model, only the coefficient for the ratio of minimum : maximum island area was significantly different from zero $(t=2.13, P=0.03)$. The coefficient was positive, indicating an increase in prevalence with a smaller range of island areas within an insular system. For terrestrial 


\begin{tabular}{llllll}
\hline Model & $\begin{array}{l}\text { Sum of squared } \\
\text { errors }\end{array}$ & $\begin{array}{l}\text { Number } \\
\text { of parameters }\end{array}$ & $\mathrm{AIC}_{\mathrm{c}}$ & $\Delta_{i}$ & $w_{i}=\frac{\exp \left(-\frac{1}{2} \Delta_{i}\right)}{\sum_{\mathrm{r}=1}^{\mathrm{R}} \exp \left(-\frac{1}{2} \Delta_{r}\right)}$ \\
\hline Island $(n=161)$ & & & & & \\
$\quad$ Physical features & 16.02 & 6 & 905.8 & 0 & 0.9968 \\
$\quad$ Range edge & 17.06 & 3 & 919.5 & 13.8 & 0.0010 \\
Colonization ability & 16.80 & 8 & 925.4 & 19.6 & 0.0000 \\
Extinction proneness & 17.09 & 4 & 922.3 & 16.5 & 0.0003 \\
Niche breadth & 16.80 & 5 & 918.8 & 13.0 & 0.0015 \\
Degree of sociality & 17.15 & 3 & 921.3 & 15.4 & 0.0004 \\
Terrestrial ( $n=176)$ & & & & & \\
$\quad$ Physical features & 22.98 & 6 & 1116.0 & 34.7 & 0.0000 \\
Range edge & 21.65 & 3 & 1088.6 & 7.3 & 0.0253 \\
Colonization ability & 22.93 & 8 & 1119.5 & 38.2 & 0.0000 \\
Extinction proneness & 23.64 & 4 & 1121.6 & 40.4 & 0.0000 \\
Niche breadth & 20.95 & 5 & 1081.2 & 0 & 0.9747 \\
Degree of sociality & 23.49 & 3 & 1117.2 & 36.0 & 0.0000 \\
\hline
\end{tabular}

\begin{tabular}{|c|c|c|c|c|c|}
\hline Model & $-2 \log _{\mathrm{e}}(L)$ & $\begin{array}{l}\text { Number } \\
\text { of parameters }\end{array}$ & $\mathrm{AIC}_{\mathrm{c}}$ & $\Delta_{i}$ & $w_{i}=\frac{\exp \left(-\frac{1}{2} \Delta_{i}\right)}{\sum_{\mathrm{r}=1}^{\mathrm{R}} \exp \left(-\frac{1}{2} \Delta_{r}\right)}$ \\
\hline \multicolumn{6}{|l|}{ Island $(n=4598)$} \\
\hline Physical features & 3786 & 28 & 3842 & 0 & 1.0000 \\
\hline Range edge & 4138 & 27 & 4192 & 350 & 0.0000 \\
\hline Colonization ability & 4079 & 32 & 4143 & 301 & 0.0000 \\
\hline Extinction proneness & 4104 & 28 & 4160 & 318 & 0.0000 \\
\hline Niche breadth & 4092 & 29 & 4150 & 308 & 0.0000 \\
\hline Degree of sociality & 4139 & 27 & 4194 & 351 & 0.0000 \\
\hline \multicolumn{6}{|l|}{ Terrestrial $(n=3252)$} \\
\hline Physical features & 3626 & 24 & 3674 & 0 & 0.9797 \\
\hline Range edge & 3820 & 23 & 3867 & 192 & 0.0000 \\
\hline Colonization ability & 3863 & 27 & 3918 & 281 & 0.0000 \\
\hline Extinction proneness & 3897 & 24 & 3946 & 271 & 0.0000 \\
\hline Niche breadth & 3632 & 25 & 3682 & 7.8 & 0.0203 \\
\hline Degree of sociality & 3888 & 23 & 3934 & 260 & 0.0000 \\
\hline
\end{tabular}

Table 2 Results of model selection for prevalence of non-volant mammals on patch networks, based on least squares regression. Separate analyses were conducted for insular systems and terrestrial patch networks. Akaike weights $\left(w_{i}\right)$ are given as a means of comparing the relative likelihoods of the competing models; the weights are normalized to sum to 1 (Burnham \& Anderson, 1998)

Table 3 Results of model selection for probability of occupancy on individual patches, based on logistic regression. Separate analyses were conducted for islands and terrestrial patches. Akaike weights $\left(w_{i}\right)$ are defined in Table 2. $L$ refers to the maximized likelihood for the model after inclusion of phylogenetic and study site effects, given the data (Burnham \& Anderson, 1998) networks, the fitted model for niche breadth explained $11.5 \%$ of the residual variation $(F=7.37$, d.f. $=3,171$, $P<0.001)$. Two of the three explanatory variables in the fitted model differed significantly from zero; $Z_{\mathrm{H}+\mathrm{D}}$ $(t=2.55, P=0.01)$ and $h(t=3.70, P<0.001)$ were both positively associated with prevalence. The fitted model for range boundary explained $8.5 \%$ of the residual variation $(F=16.08$, d.f. $=1,173, P<0.001)$, revealing that species prevalence declined in patch networks nearer the range periphery.

\section{Species occupancy of patches}

For both insular and terrestrial systems, the physical model received greater support than any of the five ecological models. For insular systems, no ecological model was deemed remotely likely to be the best model, with values of $\Delta_{i}>300$ (Table 3). For terrestrial networks, the niche- breadth model received a modest amount of support (Table 3).

The physical model yielded a reasonable fit when applied to occupancy data from islands (Nagelkerke's $R^{2}=0.26$, Hosmer and Lemeshow goodness-of-fit $\chi^{2}=11.94$, d.f. $=8, P=0.15)$. The model correctly classified $80.7 \%$ of 4598 cases. It also reduced the rate of type II error, i.e. misclassification of an occupied island as unoccupied, by $21.9 \%$ compared with the model containing only phylogeny and study site variables. Estimated coefficients indicated that probability of occupancy increased with island area $(z=17.35, P<0.001)$ and declined with distance to nearest-neighbouring islands $(z=-3.07, P=0.002)$. Results for terrestrial patches were similar. Fit of the physical model was reasonable (Nagelkerke's $R^{2}=0.24$, Hosmer and Lemeshow goodness-of-fit $\chi^{2}=11.50$, d.f. $\left.=8, P=0.18\right)$, and $71.4 \%$ of 3252 cases were classified correctly. Type II error was reduced by $26.7 \%$ compared with the phylogeny study 
site model. Predicted probability of occupancy increased with patch area $(z=13.23, P<0.001)$ and declined with distance to the nearest neighbouring patch $(z=-2.44$, $P=0.02$ ). The fit for the model of niche breadth was poor (Nagelkerke's $R^{2}=0.24$, Hosmer and Lemeshow goodnessof-fit $\chi^{2}=31.11$, d.f. $\left.=8, P<0.001\right)$, although all three explanatory variables $\left(h, Z_{\mathrm{H}+\mathrm{D}}\right.$, omnivory) displayed a significant positive association with probability of occupancy $(P<0.001$ in all cases $)$.

\section{Ecological scaling of patchiness}

For insular systems, neither the ESLIs of Vos et al. (2001, see equations 2 and 3) nor our modifications to incorporate habitat suitability and ability to disperse across an aquatic medium improved on the performance of the more parsimonious physical model (Table 4). It is possible, but not probable, that the modified ESLI model could be the best of this candidate set $\left(\Delta_{i}=5.2\right)$. Interestingly, post-hoc fitting of island occupancy data to the niche-based definition of $\mathrm{ESLI}_{C_{i}}^{*}$ used for terrestrial networks (equations 5 and 6) resulted in a model $\mathrm{AIC}_{\mathrm{c}}$ value 29 units less than the value for the model containing only physical features, indicating a superior model (Table 4). A different story emerged for mammals occupying terrestrial networks. Although the ESLI model of Vos et al. (2001) offered no improvement on the physical model, the modified ESLI model (equations 4 and 5) received much greater support than the physical model (Table 4).

The fit of the modified ESLI model to data on island occupancy was reasonable (Nagelkerke's $R^{2}=0.26$, Hosmer and Lemeshow goodness-of-fit $\chi^{2}=11.37$, d.f. $=8$, $P=0.18)$ and indicated that probability of occupancy was positively associated with $\operatorname{ESLI}_{K_{i}}^{*}(z=17.13, P<0.001)$ and $\operatorname{ESLI}_{C_{i}}^{*}(z=3.00, P=0.002)$. A $21.4 \%$ reduction in type II error was evident for the model relative to the phylogeny study site model, and $81.1 \%$ of cases were classified correctly. The fit of the post-hoc model also was good (Nagelkerke's $R^{2}=0.27$, Hosmer and Lemeshow goodnessof-fit $\chi^{2}=11.75$, d.f. $=8, P=0.17$ ) and indicated that probability of occupancy was positively associated with ESLI $_{K_{i}}^{*} \quad(z=17.68, P<0.001)$ and ESLI $_{C_{i}}^{*} \quad(z=6.59$, $P<0.001)$. A $21.9 \%$ reduction in type II error was evident for the model relative to the phylogeny study site model, and
$81.2 \%$ of cases were classified correctly. The fit of the modified ESLI model was also acceptable for data on terrestrial patch occupancy (Nagelkerke's $R^{2}=0.26$, Hosmer and Lemeshow goodness-of-fit $\chi^{2}=12.78$, d.f. $=8$, $P=0.12$ ), and $72 \%$ of cases were classified correctly. Notably, a reduction in type II error of $28.7 \%$ was observed, the largest reduction for any model. As with island data, probability of patch occupancy was positively associated with $\operatorname{ESLI}_{K_{i}}^{*}(z=13.93, P<0.001)$ and $\operatorname{ESLI}_{C_{i}}^{*}(z=6.23$, $P<0.001)$.

\section{DISCUSSION}

\section{Patterns of prevalence and occupancy}

On average, insular systems were more sparsely occupied by mammals than were more recently formed montane networks, which were more sparsely occupied than woodlot remnants formed during the last two centuries. Faunal relaxation resulting from stochastic extinction events could have contributed to this pattern. Unfortunately, isolation time covaried with physical features of the networks in our study. Thus, it is impossible to disentangle the effect on prevalence of time since formation and variation in patch area or isolation. In all likelihood, the effects of this covariation in temporal and spatial scales have acted together to produce the patterns of prevalence we observed. Likewise, our results suggest that if two networks are comparable in mean patch size and isolation but differ in their ratios of minimum : maximum patch area and isolation, the network with greater variation in patch size and isolation will be subjected to greater extinction and lower colonization rates. Thus, populations occupying insular systems, which are characterized by longer timespans since formation and greater variation in patch size and isolation than terrestrial networks, presumably have suffered from faunal relaxation accentuated by variation in the physical landscape. Less severe faunal relaxation appears to have contributed to the lower prevalence on mountaintops relative to forest remnants in farmland.

Prevalence of mammal species was most closely linked to physical features of insular systems, which is reasonable if long time periods enhance the effects of catastrophes and environmental stochasticity on persistence (Lande, 1993).
Table 4 Results of model selection for probability of occupancy of non-volant mammals on individual patches, based on logistic regression. Separate analyses were conducted for islands and terrestrial patches. The models with the lowest $\mathrm{AIC}_{\mathrm{c}}$ scores from Table 3 were compared with models containing ESLI (equations 2 and 3, with modifications described in text) and ESLI* (equations 4 and 5). Akaike weights $\left(w_{i}\right)$ are defined in Table 2. $L$ refers to the maximized likelihood for the model after inclusion of phylogenetic and study site effects, given the data (Burnham \& Anderson, 1998)

\begin{tabular}{|c|c|c|c|c|c|}
\hline Model & $-2 \log _{e}(L)$ & $\begin{array}{l}\text { Number } \\
\text { of parameters }\end{array}$ & $\mathrm{AIC}_{\mathrm{c}}$ & $\Delta_{i}$ & $w_{i}=\frac{\exp \left(-\frac{1}{2} \Delta_{i}\right)}{\sum_{\mathrm{r}=1}^{\mathrm{R}} \exp \left(-\frac{1}{2} \Delta_{r}\right)}$ \\
\hline \multicolumn{6}{|l|}{ Island ( $n=4598)$} \\
\hline Physical features & 3786 & 28 & 3842 & 0 & 0.9268 \\
\hline ESLI & 3796 & 28 & 3852 & 10 & 0.0056 \\
\hline ESLI* & 3791 & 28 & 3847 & 5 & 0.0676 \\
\hline ESLI* $^{*}$ as in terrestrial) ${ }^{\dagger}$ & 3757 & 28 & 3813 & -29 & - \\
\hline \multicolumn{6}{|l|}{ Terrestrial $(n=3252)$} \\
\hline Physical features & 3626 & 24 & 3674 & 51 & 0.0000 \\
\hline ESLI & 3716 & 24 & 3764 & 141 & 0.0000 \\
\hline ESLI* & 3575 & 24 & 3623 & 0 & 1.0000 \\
\hline
\end{tabular}

${ }^{\dagger}$ Post-hoc modelling effort; not used in selection procedure (Anderson \& Burnham, 2002). 
Interestingly, variation in island area was the sole significant predictor of prevalence. This result suggests that extinction is of greater importance than colonization in determining the structure of insular communities, and that variation in island area is important in the absence of any effect of average island size.

In contrast, prevalence of mammal species on terrestrial networks was not associated with physical features. Rather, ecological attributes associated with niche breadth and levels of adaptation to local conditions received the greatest support (Table 2). A separate analysis of thirty-two species of amphibians and mammals in an agricultural landscape revealed a similar pattern (Swihart et al., 2003). We believe the strength of these correlates with prevalence is tied principally to their influence on dispersal ability. Generalists presumably view the areas separating patches of preferred habitat as less hostile, and hence are more likely to travel through these areas than are specialists. Indeed, the success of generalists in human-altered landscapes has been tied to their ability to travel through or extract resources from the human matrix that separates native habitat remnants (Laurance, 1991; Andrén, 1994; Laurance et al., 2002). In contrast, specialists appear sensitive to structural and compositional differences between preferred habitat and matrix habitat (Lomolino \& Perault, 2001). Our measures of niche breadth were derived from studies conducted across a species' geographical range and thus lend support to the notion that broad-scale measures of niche breadth are useful indicators of a single population's ability to respond to resource heterogeneity. Close proximity of a species to its geographical range boundary had a negative influence on prevalence, as predicted if core areas of a range are more suitable for occupancy and lead to lower turnover rates (Enquist et al., 1995; Pulliam, 2000). The lower prevalence of species near range boundaries has important implications for conservation, especially in areas subjected to human disturbance (Channell \& Lomolino, 2000). Recovery plans that do not account for geographical effects on occupancy may fail if efforts are focused on populations that are responding principally to adaptive regimes at a geographical scale rather than local disturbances. Our results for mammals support the notion that selection of a core reserve network based on minimum complementary sets of species will be inadequate if several species are represented in marginal or peripheral areas of their ranges (Gaston et al., 2001).

For both insular and terrestrial networks, probability of occupancy was linked more closely to patch area and isolation than to ecological factors. Thus, results from our single-factor models supported the ties between extinctioncolonization dynamics and area-isolation attributes assumed by classical island biogeography and metapopulation paradigms (MacArthur \& Wilson, 1967; Hanski, 1994).

\section{Ecological scaling of patchiness}

Can the distributional patterns in our study be explained more readily by models that unite physical features of patch networks with ecological attributes of species? For terrestrial networks the answer is unequivocally 'yes'. The evidence is less convincing for insular systems, although it is possible that the ESLI model modified by species abilities to travel through water or over ice was superior to the physical model (Table 4). We did not attempt to differentiate species by swimming or rafting ability, attributes which may be tied to colonization ability in insular systems. We do not have an explanation for the superior fit of the post-hoc model incorporating the modified connectivity of equations 5 and 6 , although it is possible that home-range size or niche breadth are related generally to travel across inhospitable environments, including water.

In constructing a species-based model of insular zoogeography that was conceptually similar to the ESLIs of Vos et al. (2001) Lomolino (2000) noted that the validity of comparisons among networks relies on an ability to account for differences in the intervening matrix and in carrying capacities. By combining physical landscape features with ecological measures of area sensitivity (individual resource requirements and availability) and isolation sensitivity (dispersal ability mediated by niche breadth), we obtained models with greater predictive ability than the models relying solely on physical features. Specifically, species with large resource requirements or poor matches to available habitat occupied correspondingly larger patches than species with more modest resource requirements or good matches to available habitat. Likewise, mobile species with broad niches were more likely to occupy isolated patches than less mobile specialists. Our analysis thus provides additional evidence that ESLIs are superior in many instances to traditional landscape indices when the objective is predicting species occupancy (Vos et al., 2001; Opdam et al., 2002; Swihart \& Verboom, 2003).

\section{The role of stochasticity}

Our results support and extend the conclusions of studies on fewer networks and species; namely, that patterns of prevalence and occupancy in insular communities can result from non-random variation in ecological traits among species (Lomolino, 2000; Vos et al., 2001; Swihart et al., 2003; Swihart \& Verboom, 2003). However, stochasticity appears to play a dominant role in shaping these communities. Although the regression models best describing prevalence and occupancy provided reasonable fits to the data for both insular and terrestrial systems, the majority of variation in these response variables remained unexplained.

The residual variation in our models can be partitioned into two origins, natural and methodological. Addressing the former, Hubbell (2001) suggested that stochastic events are largely responsible for patterns of species prevalence and occupancy in meta and local communities. He argued that ecological drift and random dispersal were key processes governing species richness across taxa and scales, and that niche differentiation among species yielded individuals that 
were equivalent in per capita fitness. This ecological equivalence results from constraints imposed by universal scaling laws and trade-offs in life-history invariants, and serves to equalize relative fitness between species. Thus, ecological drift may override species-specific attributes in dictating patterns of species abundance in communities. Recent analyses of birds do not support the notion that ecological drift is more powerful than non-random mechanisms is shaping communities (McGill, 2003).

Several methodological issues could potentially explain some of the residual variation in our models. First, the variable sampling methods used during surveys can influence the probability of detecting a species in a patch. An important challenge awaiting future biogeographical studies is to incorporate methods of correcting for site and species differences in detection uncertainty (MacKenzie et al., 2002). Secondly, the level of phylogenetic differentiation used in our contrasts was coarse. Subfamily, tribal and generic affinities were not included in the analysis but could be important in explaining variation in patterns of occupancy or prevalence. Thirdly, no attempt was made to incorporate nonlinearities in the variables for describing the effects of a species' position within its geographical range. Theoretical models of niche shifts as a function of spatial position within a range (e.g. Pulliam, 2000) could be used to incorporate predicted nonlinear responses. Fourthly, interspecific interactions can be strong determinants of community structure at local levels and thus may explain a species' absence in suitable patches or presence in poorly suited patches (e.g. Hanski \& Zhang, 1993; Swihart et al., 2001). Many biogeographical analyses, including ours, suffer from an inability to adequately assess the role of interspecific interactions in shaping patterns of occupancy. Potential competing species covaried positively on patches in our study, rather than negatively as expected (Diamond, 1975; Lomolino, 2000). We could not examine patterns of covariation for predatorprey dyads, as most studies forming our data base focused exclusively on one trophic group. A more accurate determination of the role of stochastic events relative to deterministic factors will require improved specification of species-based models, including a consideration of interspecific interactions.

\section{ACKNOWLEDGMENTS}

We thank J. A. DeWoody and T. M. Sutton for reviewing the manucript. Accumulation of data on species was aided by E. Platt, B. Willson, and the respondents to our request for references on the list-serve of the American Society of Mammalogists. Conversations with J. Verboom regarding ecologically scaled landscape indices stimulated interest in the approach. Funding for this project and for collection of unpublished data in Indiana was provided by Purdue University, National Science Foundation grant SES-0119908, National Research Initiative Competitive Grants Program/ USDA award 93-37101-8702, and the Indiana Academy of Science.

\section{REFERENCES}

Anderson, D.R. \& Burnham, K.P. (2002) Avoiding pitfalls when using information-theoretic methods. Journal of Wildlife Management, 66, 912-918.

Anderson, A.E. \& Wallmo, O.C. (1984) Odocoileus hemionus. Mammalian Species Number 219. American Society of Mammalogists, Lawrence, KS.

Anderson, D.R., Burnham, K.P. \& Thompson, W.L. (2000) Null hypothesis testing: problems, prevalence, and an alternative. Journal of Wildlife Management, 64, 912-923.

Andrén, H. (1994) Effects of habitat fragmentation on birds and mammals in landscapes with different proportions of suitable habitat: a review. Oikos, 71, 355-366.

Anthony, R.G., Forsman, E.D., Green, G.A., Witmer, G. \& Nelson, S.K. (1987) Small mammal populations in riparian zones of different-aged coniferous forests. The Murrelet, 68, 94-102.

Armstrong, D.M. \& Jones, J.K. Jr (1971) Sorex merriami. Mammalian Species Number 2. American Society of Mammalogists.

Armstrong, D.M. \& Jones, J.K. Jr (1972) Notiosorex crawfordi. Mammalian Species Number 17. American Society of Mammalogists.

Baker, R.H. (1983) Michigan mammals. Michigan State University Press, East Lansing, MI.

Bandoli, J.H. (1987) Activity and plural occupancy of burrows in Botta's pocket gopher Thomomys bottae. American Midland Naturalist, 118, 10-14.

Barash, D.P. (1989) Marmots: social behavior and ecology. Stanford University Press, Stanford, CA.

Bartels, M.A. \& Thompson, D.P. (1993) Spermophilus lateralis. Mammalian Species Number 440. American Society of Mammalogists.

Bear, G.D. (1989) Seasonal distribution and population characteristics of elk in Estes Valley, Colorado. Colorado Division of Wildlife, 0084-8875 Number, 65, 1-14.

Bekoff, M. (1977) Canis latrans. Mammalian Species Number 79. American Society of Mammalogists.

Belant, J.L. \& Van Stappen, J.F. (2002) Island biogeography of mammals in Apostle Islands National Lakeshore, USA. Natural Areas Journal, 22, 180-185.

Belk, M.C. \& Smith, H.D. (1991) Ammospermophilus leucurus. Mammalian Species Number 368. American Society of Mammalogists.

Belovsky, G.E. (1987) Extinction models and mammalian persistence. Viable populations for conservation (ed. by M.E. Soulé), pp. 35-57. Cambridge University Press, Cambridge.

Bender, D.J., Contreras, T.A. \& Fahrig, L. (1998) Habitat loss and population decline: a meta-analysis of the patch size effect. Ecology, 79, 517-533.

Beneski, J.T. Jr \& Stinson, D.W. (1987) Sorex palustris. Mammalian Species Number 296. American Society of Mammalogists.

Bentley, J.M., Catterall, C.P. \& Smith, G.C. (2000) Effects of fragmentation of Araucarian vine forest on small mammals communities. Conservation Biology, 14, 1075-1087.

Berger, J. (1990) Persistence of different sized populations: an empirical assessment of rapid extinctions in bighorn sheep. Conservation Biology, 4, 91-98. 
Bergstrom, B.J. (1988) Home ranges of 3 species of chipmunks (Tamias) as assessed by radiotelemetry and grid trapping. Journal of Mammalogy, 69, 190-193.

Best, T.L. (1996) Lepus californicus. Mammalian Species Number 530. American Society of Mammalogists.

Best, T.L. \& Henry, T.H. (1993) Lepus alleni. Mammalian Species Number 424. American Society of Mammalogists.

Best, T.L., Bartig, J.L. \& Burt, S.L. (1992) Tamias canipes. Mammalian Species Number 411. American Society of Mammalogists.

Best, T.L., Burt, S.L. \& Bartig, J.L. (1994a) Tamias quadrivittatus. Mammalian Species Number 466. American Society of Mammalogists.

Best, T.L., Clawson, R.G. \& Clawson, J.A. (1994b) Tamias panamintinus. Mammalian Species Number 468. American Society of Mammalogists.

Best, T.L., Clawson, R.G. \& Clawson, J.A. (1994c) Tamias speciosus. Mammalian Species Number 478. American Society of Mammalogists.

von Bloeker, J.C. Jr (1967) Land mammals of the southern California islands. Proceedings of the symposium on the biology of the California islands (ed. by R.N. Philbrick), pp. 245-263. Santa Barbara Botanic Garden, Santa Barbara, CA.

Boonstra, R., Krebs, C.J., Gaines, M.S., Johnson, M.L. \& Craine, I.T.M. (1987) Natal philopatry and breeding systems in voles. Journal of Animal Ecology, 56, 655-673.

Bowman, J., Jaeger, J.A.G. \& Fahrig, L. (2002) Dispersal distance of mammals is proportional to home range size. Ecology, 83, 2049-2055.

Brown, J.H. (1978) The theory of insular biogeography and the distribution of boreal birds and mammals. Great Basin Naturalist Memoirs, 2, 209-228.

Brown, J.H. (1984) On the relationship between abundance and distribution of species. American Naturalist, 124, 255-279.

Brown, J.H. (1995) Macroecology. The University of Chicago Press, Chicago, IL.

Brown, J.H. \& Gibson, A.C. (1983) Biogeography. C. V. Mosby Company, St Louis, MO.

Brown, J.H. \& Heske, E.J. (1990) Temporal changes in a Chihuahuan Desert rodent community. Oikos, 59, 290-302.

Brown, J.H., Mehlman, D.W. \& Stevens, G.C. (1995) Spatial variation in abundance. Ecology, 76, 2028-2043.

Brown, J.H., Stevens, G.C. \& Kaufman, D.M. (1996) The geographic range: size, shape, boundaries, and internal structure. Annual Review of Ecology and Systematics, 27, 597-623.

Burnham, K.P. \& Anderson, D.R. (1998) Model selection and inference. A practical information-theoretic approach. Springer, New York, NY.

Carraway, L.N. \& Verts, B.J. (1985) Microtus oregoni. Mammalian Species Number 233. American Society of Mammalogists.

Carraway, L.N. \& Verts, B.J. (1991a) Neotoma fuscipes. Mammalian Species Number 386. American Society of Mammalogists.

Carraway, L.N. \& Verts, B.J. (1991b) Neurotrichus gibbsii. Mammalian Species Number 387. American Society of Mammalogists.

Carraway, L.N. \& Verts, B.J. (1993) Aplodontia rufa. Mammalian Species Number 431. American Society of Mammalogists.
Cervantes, F.A. (1997) Sylvilagus graysoni. Mammalian Species Number 559. American Society of Mammalogists.

Channell, R. \& Lomolino, M.V. (2000) Dynamic biogeography and conservation of endangered species. Nature, 403, 84-86.

Chapman, J.A. (1974) Sylvilagus bachmani. Mammalian Species Number 34. American Society of Mammalogists.

Chapman, J.A. (1975a) Sylvilagus nuttallii. Mammalian Species Number 56. American Society of Mammalogists.

Chapman, J.A. (1975b) Sylvilagus transitionalis. Mammalian Species Number 55. American Society of Mammalogists.

Chapman, J.A. \& Feldhamer, G.A. (1982) Wild mammals of North America: biology, management, and economics. The Johns Hopkins University Press, Baltimore, MD.

Chapman, J.A., Hockman, J.G. \& Ojeda, M.M. (1980) Sylvilagus floridanus. Mammalian Species Number 136. American Society of Mammalogists.

Churchfield, S. (1990) The natural history of shrews. Comstock Publishing Associates, Ithaca, NY.

Clark, T.W., Anderson, E., Douglas, C. \& Strickland, M. (1987) Martes americana. Mammalian Species Number 289. American Society of Mammalogists.

Clawson, R.G., Clawson, J.A. \& Best, T.L. (1994a) Tamias alpinus. Mammalian Species Number 461. American Society of Mammalogists.

Clawson, R.G., Clawson, J.A. \& Best, T.L. (1994b) Tamias quadrimaculatus. Mammalian Species Number 469. American Society of Mammalogists.

Clinchy, M., Haydon, D.T. \& Smith, A.T. (2002) Pattern does not equal process: what does patch occupancy really tell us about metapopulation dynamics? American Naturalist, 159, 351-362.

Cole, E.C., McComb, W.C., Newton, M., Leeming, J.P. \& Chambers, C.L. (1998) Response of small mammals to clearcutting, burning, and glyphosate application in the Oregon coast range. Journal of Wildlife Management, 62, 1207-1216.

Comins, H.N., Hamilton, W.D. \& May, R.M. (1980) Evolutionarily stable dispersal strategies. Journal of Theoretical Biology, 82, 205-230.

Conroy, C.J., Demboski, J.R. \& Cook, J.A. (1999) Mammalian biogeography of the Alexander Archipelago of Alaska: a north temperate nested fauna. Journal of Biogeography, 23, 343-352.

Cornely, J.E. \& Baker, R.J. (1986) Neotoma mexicana. Mammalian Species Number 262. American Society of Mammalogists.

Cornely, J.E. \& Verts, B.J. (1988) Microtus townsendii. Mammalian Species Number 325. American Society of Mammalogists.

Courchamp, F., Clutton-Brock, T. \& Grenfell, B. (1999) Inverse density dependence and the Allee effect. Trends in Ecology and Evolution, 14, 405-410.

Crowell, K.L. (1986) A comparison of relict versus equilibrium models for insular mammals of the Gulf of Maine. Biological Journal of the Linnean Society, 28, 37-64.

Cunningham, H.N. Jr (1990) Small mammals on various successional stages of disturbed lands in northeastern Ohio and northwestern Pennsylvania. Journal of the Pennsylvania Academy of Science, 64, 11-18.

Currier, M.P. (1983) Felis concolor. Mammalian Species Number 200. American Society of Mammalogists. 
Debinski, D.M. \& Holt, R.D. (2000) A survey and overview of habitat fragmentation experiments. Conservation Biology, 14, 342-355.

Demarais, S. \& Krausman, P.R. (2000) Ecology and management of large mammals in North America. Prentice Hall, Upper Saddle River, NJ.

Demarchi, M.W., Johnson, S.R. \& Searing, G.F. (2000) Distribution and abundance of mountain goats Oreamnos americanus, in westcentral British Columbia. Canadian FieldNaturalist, 114, 301-306.

Diamond, J.M. (1975) Assembly of species communities. Ecology and evolution of communities (ed. by M.L. Cody and J.M. Diamond), pp. 342-444. Harvard University Press, Cambridge, MA.

Dolan, P.G. \& Carter, D.C. (1977) Glaucomys volans. Mammalian Species Number 78. American Society of Mammalogists.

Douglas, R.J. (1976) Spatial interactions and microhabitat selections of two locally sympatric voles, Microtus montanus and Microtus pennsylvanicus. Ecology, 57, 346-352.

Doyle, A.T. (1990) Use of riparian and upland habitats by small mammals. Journal of Mammalogy, 71, 14-23.

Draper, N.R. \& Smith, H. (1998) Applied regression analysis, 3rd edn. John Wiley \& Sons, Inc., New York, NY.

Dueser, R.D. \& Brown, W.C. (1980) Ecological correlates of insular rodent diversity. Ecology, 61, 50-56.

Dunning, J.B. Jr, Borgella, R., Clements, K. \& Meffe, G.K. (1995) Patch isolation, corridor effects, and colonization by a resident sparrow in a managed pine woodland. Conservation Biology, 9, 542-550.

Durrett, R. \& Levin, S. (1994) The importance of being discrete (and spatial). Theoretical Population Biology, 46, 363-394.

Eadie, W.R. (1939) A contribution to the biology of Parascalops breweri. Journal of Mammalogy, 20, 150-173.

Eisenberg, J.F. (1981) The mammalian radiations. University of Chicago Press, Chicago, IL.

Enquist, B.J., Jordan, M.A. \& Brown, J.H. (1995) Connections between ecology, biogeography, and paleobiology: relationship between local abundance and geographic distribution in fossil and recent molluscs. Evolutionary Ecology, 9, 586-604.

Ernest, K.A. \& Mares, M.A. (1987) Spermophilus tereticaudus. Mammalian Species Number 274. American Society of Mammalogists.

Etienne, R.S. \& Heesterbeek, J.A.P. (2001) Rules of thumb for conservation of metapopulations based on a stochastic winking-patch model. American Naturalist, 158, 389-407.

Foster, J.B. (1965) The evolution of the mammals of the Queen Charlotte Islands, British Columbia. Occasional Papers of the British Columbia Provincial Museum, 14, 1-130.

Franzmann, A.W. (1981) Alces alces. Mammalian Species Number 154. American Society of Mammalogists.

Frase, B.A. \& Hoffmann, R.S. (1980) Marmota flaviventris. Mammalian Species Number 135. American Society of Mammalogists.

French, T.W. (1980) Sorex longirostris. Mammalian Species Number 143. American Society of Mammalogists.

Fritzell, E.K. \& Haroldson, K.J. (1982) Urocyon cinereoargenteus. Mammalian Species Number 189. American Society of Mammalogists.

Fuller, T.K. \& Sievert, P.R. (2001) Carnivore demography and the consequences of changes in prey availability. Carnivore conservation (ed. by J.L. Gittleman, S.M. Funk, D. Macdonald and R.K. Wayne), pp. 163-178. Cambridge University Press, Cambridge.

Galindo, C. \& Krebs, C.J. (1985) Habitat use and abundance of deer mice: interactions with meadow voles and red-backed voles. Canadian Journal of Zoology, 63, 1870-1879.

Gannon, W.L. (1988) Zapus trinotatus. Mammalian Species Number 315. American Society of Mammalogists.

Gascon, C., Lovejoy, T.E., Bierregaard, R.O. Jr, Malcolm, J.R., Stouffer, P.C., Vasconcelos, H.L., Laurance, W.F., Zimmerman, B., Tocher, M. \& Borges, S. (1999) Matrix habitat and species richness in tropical forest remnants. Biological Conservation, 91, 223-229.

Gaston, K.J., Rodrigues, A.S.L., van Rensburge, B.J., Koleff, P. \& Chown, S.L. (2001) Complementary representation and zones of ecological transition. Ecology Letters, 4, 4-9.

Gehring, T.M. (2000) Ecology of mammalian predators in a landscape fragmented by agriculture. Dissertation, Purdue University, West Lafayette, Indiana, USA.

Gehring, T.M. \& Swihart, R.K. (2003) Body size, niche breadth, and ecologically scaled responses to habitat fragmentation: mammalian predators in an agricultural landscape. Biological Conservation, 109, 283-295.

George, S.B. (1989) Sorex trowbridgii. Mammalian Species Number 337. American Society of Mammalogists.

George, S.B., Choate, J.R. \& Genoways, H.H. (1986) Blarina brevicauda. Mammalian Species Number 261. American Society of Mammalogists.

Gilbert, B.S. \& Krebs, C.J. (1991) Population dynamics of Clethrionomys and Peromyscus in southwestern Yukon 1973-1989. Holarctic Ecology, 14, 250-259.

Gliwicz, J. (1997) Space use in the root vole: basic patterns and variability. Ecography, 20, 383-389.

Goheen, J.R. (2002) North American red squirrels in the central hardwood region: the ecological implications of a range expansion. Thesis, Purdue University, West Lafayette, IN.

Gomez, D.M. \& Anthony, R.G. (1998) Small mammal abundance in riparian and upland areas of five seral stages in western Oregon. Northwest Science, 72, 293-302.

Goodman, D. (1987) The demography of chance extinction. Viable populations for conservation (ed. by M.E. Soulé), pp. 11-34. Cambridge University Press, Cambridge.

Gorman, M.L. \& Stone, R.D. (1980) The natural history of moles. Comstock Publishing Associates, Ithaca, NY.

Gottfried, B.M. (1979) Small mammal populations in woodlot islands. American Midland Naturalist, 102, 105-112.

Grayson, D.K. \& Livingston, S.D. (1993) Missing mammals on Great Basin mountains: Holocene extinctions and inadequate knowledge. Conservation Biology, 7, 527-532.

Gustafson, E.J. \& Parker, G.R. (1992) Relationships between landcover proportion and indices of landscape spatial pattern. Landscape Ecology, 7, 101-110.

Hall, E.R. (1981) The mammals of North America, 2nd edn, Vols I and II. The Blackburn Press, Caldwell, NJ.

Hallett, J.G. (1978) Parascalops breweri. Mammalian Species Number 98. American Society of Mammalogists.

Hanski, I. (1994) Patch occupancy dynamics in fragmented landscapes. Trends in Ecology and Evolution, 9, 131-135.

Hanski, I. (1998) Metapopulation dynamics. Nature, 396, 41-49. 
Hanski, I. (1999) Metapopulation ecology. Oxford University Press, Oxford, UK.

Hanski, I. \& Ovaskainen, O. (2000) The metapopulation capacity of a fragmented landscape. Nature, 404, 755-758.

Hanski, I. \& Zhang, D. (1993) Migration, metapopulation dynamics and fugitive coexistence. Journal of Theoretical Biology, 163, 491-504.

Hanski, I., Hansson, L. \& Henttonen, H. (1991) Specialist predators, generalist predators, and the microtine rodent cycle. Journal of Animal Ecology, 60, 353-367.

Hart, E.B. (1992) Tamias dorsalis. Mammalian Species Number 399. American Society of Mammalogists.

Hartman, G.D. \& Krenz, J.D. (1993) Estimating population density of moles Scalopus aquaticus using assessment lines. Acta Theriologica, 38, 305-314.

Harvey, P.H. \& Pagel, M.D. (1991) The comparative method in evolutionary biology. Oxford University Press, Oxford, UK.

Hatt, R.T., Van Tyne, J., Stuart, L.C., Pope, C.H. \& Grobman, A.B. (1948) Island life: a study of the land vertebrates of the islands of eastern Lake Michigan. Cranbrook Institute of Science Bulletin Number, 27, 1-166.

Hayes, R.D. \& Harestad, A.S. (2000) Wolf functional response and regulation of moose in the Yukon. Canadian Journal of Zoology, 78, 60-66.

Hays, W.S.T. \& Lidicker, W.Z. Jr (2000) Winter aggregations, Dehnel effect, and habitat relations in the Suisun shrew Sorex ornatus sinuosus. Acta Theriologica, 45, 433-442.

Hilton, C.D. \& Best, T.L. (1993) Tamias cinereicollis. Mammalian Species Number 436. American Society of Mammalogists.

Hoffmann, R.S. \& Owen, J.G. (1980) Sorex tenellus and Sorex nanus. Mammalian Species Number 131. American Society of Mammalogists.

Holling, C.S. (1992) Cross-scale morphology, geometry, and dynamics of ecosystems. Ecological Monographs, 62, 447-502.

Hubbell, S.P. (2001) The unified neutral theory of biodiversity and biogeography. Monographs in Population Biology Number 32. Princeton University Press, Princeton, NJ.

Ivan, J.S. \& Swihart, R.K. (2000) Selection of mast by granivorous rodents of the central hardwood forest region. Journal of Mammalogy, 81, 549-562.

Jenkins, S.H. \& Busher, P.E. (1979) Castor canadensis. Mammalian Species Number 120. American Society of Mammalogists.

Jenkins, S.H. \& Eshelman, B.D. (1984) Spermophilus beldingi. Mammalian Species Number 221. American Society of Mammalogists.

Johnson, D.W. \& Armstrong, D.M. (1987) Peromyscus crinitus. Mammalian Species Number 287. American Society of Mammalogists.

Kelt, D.A. \& Van Vuren, D. (1999) Energetic constraints and the relationship between body size and home range area in mammals. Ecology, 80, 337-340.

Kelt, D.A. \& Van Vuren, K. (2001) The ecology and macroecology of mammalian home range area. American Naturalist, 157, 637-645.

King, C.M. (1983) Mustela erminea. Mammalian Species Number 195. American Society of Mammalogists.

King, C. (1989) The natural history of weasels and stoats. Comstock Publishing Associates, Ithaca, NY.
Kinlaw, A. (1995) Spilogale putoris. Mammalian Species Number 511. American Society of Mammalogists.

Kirkland, G.L. Jr \& Layne, J.N. (eds) (1989) Advances in the study of Peromyscus (Rodentia). Texas Tech University Press, Lubbock, TX.

Knutson, M.G., Sauer, J.R., Olsen, D.A., Mossman, M.J., Hemesath, L.M. \& Lannoo, M.J. (1999) Effects of landscape composition and wetland fragmentation on frog and toad abundance and species richness in Iowa and Wisconsin, USA. Conservation Biology, 13, 1437-1446.

Koprowski, J.L. (1994) Sciurus carolinensis. Mammalian Species Number 480. American Society of Mammalogists.

Krebs, C.J. \& Wingate, I. (1985) Population fluctuations in the small mammals of the Kluane Region, Yukon Territory. Canadian Field-Naturalist, 99, 51-61.

Kurta, A. (1995) Mammals of the Great Lakes region, revised edition. The University of Michigan Press, Ann Arbor, MI.

Kwiecinski, G.G. (1998) Marmota monax. Mammalian Species Number 591. American Society of Mammalogists.

Lackey, J.A. (1991a) Chaetodipus arenarius. Mammalian Species Number 384. American Society of Mammalogists.

Lackey, J.A. (1991b) Chaetodipus spinatus. Mammalian Species Number 385. American Society of Mammalogists.

Lackey, J.A. (1996) Chaetodipus fallax. Mammalian Species Number 517. American Society of Mammalogists.

Lackey, J.A., Huckaby, D.G. \& Ormiston, B.G. (1985) Peromyscus leucopus. Mammalian Species Number 247. American Society of Mammalogists.

Lambin, X. \& Krebs, C.J. (1991) Spatial organization and mating system of Microtus townsendii. Behavioral Ecology and Sociobiology, 28, 353-363.

Lambin, X. \& Krebs, C.J. (1993) Influence of female relatedenss on the demography of Townsend's vole populations in spring. Journal of Animal Ecology, 62, 536-550.

Lambin, X., Krebs, C.J. \& Scott, B. (1992) Spacing system of the tundra vole (Microtus oeconomus) during the breeding season in Canada's western Arctic. Canadian Journal of Zoology, 70, 2068-2072.

Lande, R. (1993) Risks of population extinction from demographic and environmental stochasticity and random catastrophes. American Naturalist, 142, 911-927.

Lapasha, D.G. \& Powell, R.A. (1994) Pine vole (Microtus pinetorum) movement toward areas in apple orchards with reduced populations. Journal of Horticultural Science, 69, 1077-1082.

Larivière, S. \& Pasitschniak-Arts, M. (1996) Vulpes vulpes. Mammalian Species Number 537. American Society of Mammalogists.

Larivière, S. \& Walton, L.R. (1997) Lynx rufus. Mammalian Species Number 563. American Society of Mammalogists.

Larivière, S. \& Walton, L.R. (1998) Lontra canadensis. Mammalian Species Number 587. American Society of Mammalogists.

Laurance, W.F. (1991) Ecological correlates of extinction proneness in Australian tropical rain forest mammals. Conservation Biology, 5, 79-89.

Laurance, W.F. (1995) Extinction and survival of rainforest mammals in a fragmented tropical landscape. Landscape approaches in mammalian ecology and conservation 
(ed. by W.Z. Lidicker Jr), pp. 46-63. University of Minnesota Press, Minneapolis, MN.

Laurance, W.F., Lovejoy, T.E., Vasconcelos, H.L., Bruna, E.M., Didham, R.K., Stouffer, P.C., Gascon, C., Bierregaard, R.O., Laurance, S.G. \& Sampaio, E. (2002) Ecosystem decay of Amazonian forest fragments: a 22-year investigation. Conservation Biology, 16, 605-618.

Lawes, M.J., Mealin, P.E. \& Piper, S.E. (2000) Patch occupancy and potential metapopulation dynamics of three forest mammals in fragmented Afromontane forest in South Africa. Conservation Biology, 14, 1088-1098.

Lawlor, T.E. (1983) The mammals. Island biogeography in the Sea of Cortez (ed. by T.J. Case and M.L. Cody), pp. 265-289, 482-500. University of California Press, Berkeley, CA.

Lawlor, T.E. (1986) Comparative biogeography of mammals on islands. Biological Journal of the Linnean Society, 28, 99-125.

Levin, S.A. (1992) The problem of pattern and scale in ecology. Ecology, 73, 1943-1967.

Levins, R. (1969) Some demographic and genetic consequences of environmental heterogeneity for biological control. Bulletin of the Entomological Society of America, 15, 237-240.

Lim, B.K. (1987) Lepus townsendii. Mammalian Species Number 288. American Society of Mammalogists.

Linzey, A.V. (1983) Synaptomys cooperi. Mammalian Species Number 210. American Society of Mammalogists.

Lomolino, M.V. (1986) Mammalian community structure on islands: the importance of immigration, extinction and interactive effects. Biological Journal of the Linnean Society, $28,1-21$.

Lomolino, M.V. (2000) A species-based theory of insular zoogeography. Global Ecology and Biogeography, 9, 39-58.

Lomolino, M.V. \& Perault, D.R. (2001) Island biogeography and landscape ecology of mammals inhabiting fragmented, temperate rain forests. Global Ecology and Biogeography, 10, 113-132.

Lomolino, M.V., Brown, J.H. \& Davis, R. (1989) Island biogeography of montane forest mammals in the American southwest. Ecology, 70, 180-194.

Long, C.A. (1974) Microsorex hoyi and Microsorex thompsoni. Mammalian Species Number 33. American Society of Mammalogists.

Lotze, J. \& Anderson, S. (1979) Procyon lotor. Mammalian Species Number 119. American Society of Mammalogists.

Ludwig, D.R. (1984) Microtus richardsoni. Mammalian Species Number 223. American Society of Mammalogists.

Lynam, A.J. \& Billick, I. (1999) Differential responses of small mammals to fragmentation in a Thailand tropical forest. Biological Conservation, 91, 191-200.

MacArthur, R.H. \& Wilson, E.O. (1967) The theory of island biogeography. Monographs in Population Biology Number 1. Princeton University Press, Princeton, NJ.

MacCracken, J.G., Uresk, D.W. \& Hansen, R.M. (1985) Habitat used by shrews in southeastern Montana. Northwest Science, 59, 24-27.

Macêdo, R.H. \& Mares, M.A. (1988) Neotoma albigula. Mammalian Species Number 310. American Society of Mammalogists.

MacKenzie, D.I., Nichols, J.D., Lachman, G.B., Droege, S., Royle, J.A. \& Langtimm, C.A. (2002) Estimating site occupancy rates when detection probabilities are less than one. Ecology, 83, 2248-2255.

Manly, B., McDonald, L. \& Thomas, D. (1993) Resource selection by animals. Chapman \& Hall, London, UK.

Matthiae, P.E. \& Stearns, F. (1981) Mammals in forest islands in southeastern Wisconsin. Forest island dynamics in mandominated landscapes (ed. by R.L. Burgess and D.M. Sharpe), pp. 55-66. Springer-Verlag, New York, NY.

McAllister, J.A. \& Hoffmann, R.S. (1988) Phenacomys intermedius. Mammalian Species Number 305. American Society of Mammalogists.

McCabe, T.T. \& Cowan, I.M. (1945) Peromyscus maniculatus macrorhinus and the problem of insularity. Transactions of the Royal Canadian Institute, 25, 117-215.

McComb, W.C., McGarigal, K. \& Anthony, R.G. (1993) Small mammal and amphibian abundance in streamside and upslope habitats of mature Douglas-fir stands, western Oregon. Northwest Science, 67, 7-15.

McCorquodale, S.M., Raedeke, K.J. \& Taber, R.D. (1989) Home ranges of elk in an arid environment. Northwest Science, 63, 29-34.

McDonald, K.A. \& Brown, J.H. (1992) Using montane mammals to model extinctions due to global change. Conservation Biology, 6, 409-415.

McGill, B.J. (2003) A test of the unified neutral theory of biodiversity. Nature, 422, 881-885.

McGlynn, T.P., Hoover, J.R., Jasper, G.S., Kelly, M.S., Polis, A.M., Spangler, C.M. \& Watson, B.J. (2002) Resource heterogeneity affects demography of the Costa Rican ant Aphaenogaster araneoides. Journal of Tropical Ecology, 18, 231-244.

McManus, J.J. (1974) Didelphis virginiana. Mammalian Species Number 40. American Society of Mammalogists.

Mech, L.D. (1970) The wolf: the ecology and behavior of an endangered species. University of Minnesota Press, Minneapolis, MN.

Mech, L.D. (1974) Canis lupus. Mammalian Species Number 37. American Society of Mammalogists.

Merritt, J.F. (1981) Clethrionomys gapperi. Mammalian Species Number 146. American Society of Mammalogists.

Minchinton, T.E. (1997) Life on the edge: conspecific attraction and recruitment of populations to disturbed habitats. Oecologia (Berlin), 111, 45-52.

Moore, C.M. \& Collins, P.W. (1995) Urocyon littoralis. Mammalian Species Number 489. American Society of Mammalogists.

Mumford, R.E. \& Whitaker, J.O. Jr (1982) Mammals of Indiana. Indiana University Press, Bloomington, IN.

Murie, J.O. \& Michener, G.R. (eds) (1984) The biology of ground-dwelling squirrels. University of Nebraska Press, Lincoln, NE.

Nagelkerke, C.J., Verboom, J., van den Bosch, F. \& van de Wolfshaar, K. (2002) Time lags in metapopulation responses to landscape change. Concepts and application of landscape ecology in biological conservation (ed. by K.J. Gutzwiller), pp. 330-354. Springer-Verlag, New York, NY.

Nagorsen, D.W. (1987) Marmota vancouverensis. Mammalian Species Number 270. American Society of Mammalogists.

Nash, D.J. \& Seaman, R.N. (1977) Sciurus aberti. Mammalian Species Number 80. American Society of Mammalogists. 
Negus, N.C., Berger, P.J. \& Brown, B.W. (1986) Microtine population dynamics in a predictable environment. Canadian Journal of Zoology, 64, 785-792.

Novikov, E. \& Moshkin, M. (1998) Sexual maturation, adrenocortical function and population density of red-backed vole, Clethrionomys rutilus (Pall.). Mammalia, 64, 529-540.

Nupp, T.E. \& Swihart, R.K. (2000) Landscape-level correlates of small-mammal assemblages in forest fragments of farmland. Journal of Mammalogy, 81, 512-526.

Oaks, E.C., Young, P.J., Kirkland, G.L. Jr \& Schmidt, D.F. (1987) Spermophilus variegatus. Mammalian Species Number 272. American Society of Mammalogists.

Olding, R.J. \& Cockrum, E.L. (1977) Estimation of desert rodent populations by intensive removal. Journal of the Arizona Academy of Science, 12, 94-108.

Opdam, P., Verboom, J. \& Pouwels, R. (2003) Landscape cohesion assessment. Landscape Ecology, in press .

Owen, J.G. \& Hoffmann, R.S. (1983) Sorex ornatus. Mammalian Species Number 212. American Society of Mammalogists.

Pasitschniak-Arts, M. (1993) Ursus arctos. Mammalian Species Number 439. American Society of Mammalogists.

Pasitschniak-Arts, M. \& Larivière, S. (1995) Gulo gulo. Mammalian Species Number 499. American Society of Mammalogists.

Patterson, B.D. (1984) Mammalian extinction and biogeography in the southern Rocky Mountains. Extinctions (ed. by M.H. Nitecki), pp. 247-293. University of Chicago Press, Chicago, IL.

Patterson, B.D. \& Atmar, W. (1986) Nested subsets and the structure of insular mammalian faunas and archipelagos. Biological Journal of the Linnean Society, 28, 65-82.

Patterson, B.D. \& Brown, J.H. (1991) Regionally nested patterns of species composition in granivorous rodent assemblages. Journal of Biogeography, 18, 395-402.

Paulson, D.D. (1988) Chaetodipus baileyi. Mammalian Species Number 297. American Society of Mammalogists.

Petersen, K.E. \& Yates, T.L. (1980) Condylura cristata. Mammalian Species Number 129. American Society of Mammalogists.

Pinter, A.J. (1988) Multiannual fluctuations in precipitation and population dynamics of the montane vole, Microtus montanus. Canadian Journal of Zoology, 66, 2128-2132.

Poglayen-Neuwall, I. \& Toweill, D.E. (1988) Bassariscus astutus. Mammalian Species Number 327. American Society of Mammalogists.

Powell, R.A. (1981) Martes pennanti. Mammalian Species Number 156. American Society of Mammalogists.

Powell, R.A. (1993) The fisher: life history, ecology, and behavior, 2nd edn. University of Minnesota Press, Minneapolis, MN.

Pulliam, H.R. (2000) On the relationship between niche and distribution. Ecology Letters, 3, 349-361.

Ray, C., Gilpin, M. \& Smith, A.T. (1991) The effect of conspecific attraction on metapopulation dynamics. Biological Journal of the Linnean Society, 42, 123-134.

Redfield, J.A. (1976) Distribution, abundance, size, and genetic variation of Peromyscus maniculatus on the Gulf Islands of British Columbia. Canadian Journal of Zoology, 54, 463474.
Reich, L.M. (1981) Microtus pennsylvanicus. Mammalian Species Number 159. American Society of Mammalogists.

Reid, D.G., Code, T.E., Reid, A.C.H. \& Herrero, S.M. (1994) Spacing, movements, and habitat selection of the river otter in boreal Alberta. Canadian Journal of Zoology, 72, 1314-1324.

Revilla, E. \& Palomares, F. (2002) Spatial organization, group living and ecological correlates in low-density populations of Eurasian badgers, Meles meles. Journal of Animal Ecology, 71, 497-512.

Richens, V.B. (1974) Numbers and habitat affinities of small mammals in northwestern Maine. Canadian Field-Naturalist, 88, 191-196.

Rickart, E.A. \& Heaney, L.R. (2001) Shrews of the La Sal Mountains, southeastern Utah. Western North American Naturalist, 61, 103-108.

Ricketts, T.H., Dinerstein, E. Olson, D.M., Loucks, C.J., Eichbaum, W., DellaSala, D., Kavanagh, K., Hedao, P., Hurley, P.T., Carney, K.M., Abell, R. \& Walters, S. (1999) Terrestrial ecoregions of North America. Island Press, Washington, DC.

Rideout, C.B. \& Hoffmann, R.S. (1975) Oreamnos americanus. Mammalian Species Number 63. American Society of Mammalogists.

Rosenblatt, D.L., Heske, E.J., Neslon, S.L., Barber, D.M., Miller, M.A. \& MacAllister, B. (1999) Forest fragments in east-central Illinois: islands or habitat patches for mammals? American Midland Naturalist, 141, 115-123.

Rosenzweig, M.L. (1995) Species diversity in space and time. Cambridge University Press, Cambridge.

Ruggiero, L.F., Aubry, K.B., Buskirk, S.W., Lyon, L.J. \& Zielinski, W.J. (eds) (1994) The scientific basis for conserving forest carnivores. American marten, fisher, lynx, and wolverine in the western United States. United States Department of Agriculture Forest Service General Technical Report RM254, Fort Collins, CO.

Sarre, S., Smith, G.T. \& Meyers, J.A. (1995) Persistence of two species of gecko (Oedura reticulata and Gehyra variegata) in remnant habitat. Biological Conservation, 71, 25-33.

Schumaker, N.H. (1996) Using landscape indices to predict habitat connectivity. Ecology, 77, 1210-1225.

Schweiger, S. \& Boutin, S. (1995) The effects of winter food addition on the population dynamics of Clethrionomys rutilus. Canadian Journal of Zoology, 73, 419-426.

Schwilk, D.W. \& Keeley, J.E. (1998) Rodent populations after a large wildfire in California chaparral and coastal sage scrub. The Southwestern Naturalist, 43, 480-483.

Sheffield, S.R. \& King, C.M. (1994) Mustela nivalis. Mammalian Species Number 454. American Society of Mammalogists.

Sheffield, S.R. \& Thomas, H.H. (1997) Mustela frenata. Mammalian Species Number 570. American Society of Mammalogists.

Sheperd, B.F. \& Swihart, R.K. (1995) Spatial dynamics of fox squirrels (Sciurus niger) in fragmented landscapes. Canadian Journal of Zoology, 73, 2098-2105.

Slough, B.G. \& Mowat, G. (1996) Lynx population dynamics in an untrapped refugium. Journal of Wildlife Management, 60, 946-961.

Smith, W.P. (1991) Odocoileus virginianus. Mammalian Species Number 388. American Society of Mammalogists. 
Smith, F.A. (1997) Neotoma cinerea. Mammalian Species Number 564. American Society of Mammalogists.

Smith, M.E. \& Belk, M.C. (1996) Sorex monticolus. Mammalian Species Number 528. American Society of Mammalogists.

Smith, A.T. \& Peacock, M.M. (1990) Conspecific attraction and the determination of metapopulation colonization rates. Conservation Biology, 4, 320-323.

Smith, A.T. \& Weston, M.L. (1990) Ochotona princeps. Mammalian Species Number 352. American Society of Mammalogists.

Smolen, M.J. (1981) Microtus pinetorum. Mammalian Species Number 147. American Society of Mammalogists.

Smolen, M.J. \& Keller, B.L. (1987) Microtus longicaudus. Mammalian Species Number 271. American Society of Mammalogists.

Snyder, D.P. (1982) Tamias striatus. Mammalian Species Number 168, American Society of Mammalogists.

Stalling, D.T. (1990) Microtus ochrogaster. Mammalian Species Number 355. American Society of Mammalogists.

Steele, M.A. (1998) Tamiasciurus budsonicus. Mammalian Species Number 586. American Society of Mammalogists.

Stuart-Smith, A.K., Bradshaw, C.J.A., Boutin, S., Hebert, D.M. \& Rippin, A.B. (1997) Woodland caribou relative to landscape patterns in northeastern Alberta. Journal of Wildlife Management, 61, 622-633.

Sullivan, T.P., Sullivan, D.S., Lautenschlager, R.A. \& Wagner, R.G. (1997) Long-term influence of glyphosate herbicide on demography and diversity of small mammal communities in coastal coniferous forest. Northwest Science, 71, 6-17.

Sullivan, T.P., Sullivan, D.S. \& Hogue, E.J. (2001) Influence of diversionary foods on vole (Microtus montanus and Microtus longicaudus) populations and feeding damage to coniferous tree seedlings. Crop Protection, 20, 103-112.

Sutherland, G.D., Harestad, A.S., Price, K. \& Lertzman, K.P. (2000) Scaling of natal dispersal distances in terrestrial birds and mammals. Conservation Ecology, 4, 16. [online] URL: http://www.consecol.org/vol4/iss1/art16.

Sutton, D.A. (1992) Tamias amoenus. Mammalian Species Number 390. American Society of Mammalogists.

Sutton, D.A. (1993) Tamias townsendii. Mammalian Species Number 435. American Society of Mammalogists.

Swihart, R.K. (1992) Home-range attributes and spatial structure of woodchuck populations. Journal of Mammalogy, 73, 604-618.

Swihart, R.K. \& Nupp, T.E. (1998) Modeling population responses of North American tree squirrels to agriculturally induced forest fragmentation. Ecology of tree squirrels (ed. by M.A. Steele, J.F. Merritt and D.A. Zegers), pp. 1-19. Virginia Museum of Natural History Special Publication Number 6. Martinsville, VA.

Swihart, R.K. \& Verboom, J. (2003) Using ecologically scaled landscape indices to assess biodiversity consequences of landuse decisions. Conserving biodiversity in agricultural landscapes: model-based planning tools (ed. by R.K. Swihart and J.E. Moore). Purdue University Press, West Lafayette, IN. In press.

Swihart, R.K., Feng, Z., Slade, N.A. Mason, D. \& Gehring, T.M. (2001) Effects of habitat destruction and resource supplementation in a predator-prey metapopulation model. Journal of Theoretical Biology, 210, 287-303.
Swihart, R.K., Gehring, T.M., Kolozsvary, M.B. \& Nupp, T.E. (2003) Responses of 'resistant' vertebrates to habitat loss and fragmentation: the importance of niche breadth and range boundaries. Diversity and Distributions, 9, 1-18.

Tamarin, R.H., editor. (1985) Biology of New World Microtus. Special Publication Number 8. American Society of Mammalogists.

Ter Braak, C.J.F., Hanski, I. \& Verboom, J. (1998) The incidence function approach to modeling of metapopulation dynamics. Modeling spatiotemporal dynamics in ecology (ed. by J. Bascompte and R.V. Sole), pp. 167-188. SpringerVerlag, Berlin, Germany.

Thompson, S.D. (1982) Spatial utilization and foraging behavior of the desert woodrat, Neotoma lepida lepida. Journal of Mammalogy, 63, 570-581.

Ticul, A. \& Arroyo-Cabrales, J. (1990) Cálculos de captura, densidad y ámbito hogareño de tres especies de roedores en una área de influencia humana en el sureste de Durango, México. Anales de la Escuela Nacional de Ciencias Biologicas, 33, 185-210.

Tilman, D., May, R.M., Lehman, C.L. \& Nowak, M.A. (1994) Habitat destruction and the extinction debt. Nature, 371, 65-66.

Tischendorf, L. \& Fahrig, L. (2000a) How should we measure landscape connectivity? Landscape Ecology, 15, 633-641.

Tischendorf, L. \& Fahrig, L. (2000b) On the usage and measurement of landscape connectivity. Oikos, 90, 7-19.

Tumlison, R. (1987) Felis lynx. Mammalian Species Number 269. American Society of Mammalogists.

Tyutyunov, Y., Dombrovsky, Y., Arditi, R. \& Surkov, F. (1996) The influence of dispersal behaviour on metapopulation viability. Journal of Biological Systems, 4, 277-290.

Urban, D. \& Keitt, T. (2001) Landscape connectivity: a graphtheoretic perspective. Ecology, 82, 1205-1218.

Veal, R. \& Caire, W. (1979) Peromyscus eremicus. Mammalian Species Number 118. American Society of Mammalogists.

Verts, B.J. \& Carraway, L.N. (2002) Neotoma lepida. Mammalian Species Number 699. American Society of Mammalogists.

Viitala, J. (1994) Monogamy in free living Microtus oeconomus. Annales Zoologici Fennici, 31, 343-345.

Vos, C.C., Verboom, J., Opdam, P.F.M. \& Ter Braak, C.J.F. (2001) Toward ecologically scaled landscape indices. American Naturalist, 157, 24-41.

Wade-Smith, J. \& Verts, B.J. (1982) Mephitis mephitis. Mammalian Species Number 173. American Society of Mammalogists.

Webster, W.D. \& Jones, J.K. Jr (1982) Reithrodontomys megalotis. Mammalian Species Number 167. American Society of Mammalogists.

Wells-Gosling, N. \& Heaney, L.R. (1984) Glaucomys sabrinus. Mammalian Species Number 229. American Society of Mammalogists.

Wheatley, M. (1997) Beaver, Castor canadensis, home range size and patterns of use in the taiga of southeastern Manitoba: III. Habitat variation. Canadian Field-Naturalist, 111, $217-$ 222.

Whitaker, J.O. Jr (1972) Zapus hudsonius. Mammalian Species Number 11. American Society of Mammalogists.

Whitaker, J.O. Jr (1974) Cryptotis parva. Mammalian Species Number 43. American Society of Mammalogists. 
Whitaker, J.O. Jr \& Wrigley, R.E. (1972) Napaeozapus insignis. Mammalian Species Number 14. American Society of Mammalogists.

Williams, D.F. (1984) Habitat associations of some rare shrews (Sorex) from California. Journal of Mammalogy, 65, 325328.

Willner, G.R., Feldhamer, G.A., Zucker, E.E. \& Chapman, J.A. (1980) Ondatra zibethicus. Mammalian Species Number 141. American Society of Mammalogists.

Wilson, D.E. (1991) Mammals of the Tres Marias Islands. Contributions to mammalogy in honor of Karl F. Koopman (ed. by T.A. Griffiths and D. Klingener), pp. 214-250. Bulletin of the American Museum of Natural History 206. Washington, DC.

Wilson, D.E. \& Reeder, D.M. (eds) (1993) Mammal species of the world, 2nd edn. Smithsonian Institution Press, Washington, DC.

Wilson, D.E. \& Ruff, S. (eds) (1999) The Smithsonian book of North American mammals. Smithsonian Institution Press, Washington, DC.

Wolfe, J.L. (1982) Oryzomys palustris. Mammalian Species Number 176. American Society of Mammalogists.

Wolff, J.O. (1999) Behavioral model systems. Landscape ecology of small mammals (ed. by G.W. Barrett and J.D. Peles), pp. 11-40. Springer, New York, NY.

Woods, C.A. (1973) Erethizon dorsatum. Mammalian Species Number 29. American Society of Mammalogists.

Wright, D.H., Patterson, B.D., Mikkelson, G.M., Cutler, A. \& Atmar, W. (1998) A comparative analysis of nested subset patterns of species composition. Oecologia, 113, 1-20.

Yates, T.L. \& Schmidly, D.J. (1978) Scalopus aquaticus. Mammalian Species Number 105. American Society of Mammalogists.

Zegers, D.A. (1984) Spermophilus elegans. Mammalian Species Number 214. American Society of Mammalogists.

\section{BIOSKETCHES}

Robert K. Swihart is a professor of wildlife ecology. His research interests include mammalian ecology and conservation-based land-use planning.

Todd C. Atwood has an MS in wildlife science from Purdue University and currently is a PhD student. His research interests include vertebrate behavioural ecology.

Jacob R. Goheen has an MS in wildlife science from Purdue University and currently is a $\mathrm{PhD}$ student. He is interested in how local phenomena influence the distribution and abundance of species at broader spatial scales.

Daniel M. Scheiman has an MS from Eastern Illinois University and currently is working on his $\mathrm{PhD}$ in avian ecology. His primary research interests are in grassland bird ecology.

Karen E. Munroe has an MS degree from Purdue University and currently is working towards her $\mathrm{PhD}$. Her research interests are in mating systems and dispersal of small mammals.

Thomas M. Gehring has a PhD in wildlife ecology from Purdue University and is an Assistant Professor of wildlife biology. His research focuses on predator ecology in human-dominated systems. 
Appendix Biological attributes for species of North American mammals used in occupancy and prevalence analyses. Scientific names follow Wilson \& Reeder (1993). Ter, terrestrial; Saq, semi-aquatic; Sar, semi-arboreal; Sfo, semi-fossorial; Gli, gliding. A species receiving a value of zero for all five variables was designated as fossorial

\begin{tabular}{|c|c|c|c|c|c|c|c|c|c|c|c|c|}
\hline Species & Ter & Saq & Sar & Sfo & Gli & $\begin{array}{l}\text { Dispersal } \\
(\mathrm{km})\end{array}$ & $\begin{array}{l}\text { Home range } \\
\left(\mathrm{km}^{2}\right)\end{array}$ & $\begin{array}{l}\text { Body } \\
\text { size }(\mathrm{kg})\end{array}$ & $\begin{array}{l}\text { Population density } \\
\text { (individuals } \mathrm{km}^{-2} \text { ) }\end{array}$ & Sociality & Habitats & Diet \\
\hline Alces alces & 1 & 0 & 0 & 0 & 0 & 118 & 47 & 600 & 1.5 & 1 & 3 & 2 \\
\hline Ammospermophilus leucurus & 0 & 0 & 0 & 1 & 0 & & 0.06167 & 0.10585 & 20.5 & 0 & 4 & 5 \\
\hline Aplodontia rufa & 0 & 0 & 0 & 0 & 0 & & 0.00183 & 0.806 & 946 & 0 & 3 & 2 \\
\hline Bassariscus astutus & 1 & 0 & 0 & 0 & 0 & & 0.5 & 0.94 & 3.5 & 1 & 4 & 5 \\
\hline Blarina brevicauda & 0 & 0 & 0 & 1 & 0 & & 0.025 & 0.016 & 3925 & 1 & 5 & 4 \\
\hline Canis latrans & 1 & 0 & 0 & 0 & 0 & 176 & 10.5 & 14.5 & 0.7 & 3 & 10 & 5 \\
\hline Canis lupus & 1 & 0 & 0 & 0 & 0 & 79 & 65 & 28 & 0.02 & 3 & 4 & 2 \\
\hline Castor canadensis & 0 & 1 & 0 & 0 & 0 & 40.6 & 0.1108 & 18.5 & 3.6 & 3 & 7 & 2 \\
\hline Cervus elaphus & 1 & 0 & 0 & 0 & 0 & 18.5 & 159 & 280 & 13.5 & 2 & 4 & 3 \\
\hline Chaetodipus arenarius & 1 & 0 & 0 & 0 & 0 & & 0.003 & 0.0185 & 1551 & 0 & 1 & 4 \\
\hline Chaetodipus baileyi & 1 & 0 & 0 & 0 & 0 & & 0.003 & 0.0264 & 4085 & 0 & 2 & 4 \\
\hline Chaetodipus fallax & 1 & 0 & 0 & 0 & 0 & & 0.003 & 0.0195 & 1785 & 0 & 2 & 4 \\
\hline Chaetodipus intermedius & 1 & 0 & 0 & 0 & 0 & & 0.003 & 0.0152 & 235 & 0 & 2 & 4 \\
\hline Chaetodipus penicillatus & 1 & 0 & 0 & 0 & 0 & & 0.003 & 0.016 & 98 & 0 & 2 & 4 \\
\hline Chaetodipus spinatus & 1 & 0 & 0 & 0 & 0 & & 0.003 & 0.0155 & 1551 & 0 & 2 & 4 \\
\hline Clethrionomys gapperi & 1 & 0 & 0 & 0 & 0 & & 0.0077 & 0.0275 & 1000 & 0 & 2 & 2 \\
\hline Clethrionomys rutilus & 1 & 0 & 0 & 0 & 0 & & 0.003 & 0.03 & 1331 & 0 & 2 & 3.5 \\
\hline Condylura cristata & 0 & 1 & 0 & 0 & 0 & & 0.004 & 0.056 & 2500 & 3 & 2 & 2 \\
\hline Cryptotis parva & 0 & 0 & 0 & 1 & 0 & & 0.000023 & 0.004 & 1798 & 3 & 4 & 3 \\
\hline Didelphis virginiana & 1 & 0 & 0 & 0 & 0 & 4.3 & 0.2 & 3.75 & 26 & 0 & 4 & 5 \\
\hline Dipodomys merriami & 1 & 0 & 0 & 0 & 0 & 0.2 & 0.00125 & 0.04315 & 1100 & 1 & 3 & 4 \\
\hline Erethizon dorsatum & 0 & 0 & 1 & 0 & 0 & & 1.5712 & 6.8 & 5.1 & 1 & 6 & 2 \\
\hline Felis concolor & 1 & 0 & 0 & 0 & 0 & 155 & 409 & 43.7 & 0.02 & 0 & 5 & 3 \\
\hline Glaucomys sabrinus & 0 & 0 & 0 & 0 & 1 & & 0.01 & 0.107 & 550 & 1 & 3 & 4 \\
\hline Glaucomys volans & 0 & 0 & 0 & 0 & 1 & & 0.0114 & 0.07 & 700 & 1 & 4 & 4 \\
\hline Gulo gulo & 1 & 0 & 0 & 0 & 0 & 300 & 374 & 14.5 & 0.005 & 0 & 1 & 3 \\
\hline Lepus alleni & 1 & 0 & 0 & 0 & 0 & & 6.428 & 3.783 & 18.8 & 1 & 2 & 2 \\
\hline Lepus americanus & 1 & 0 & 0 & 0 & 0 & 20.1 & 0.088 & 1.7 & 2000 & 0 & 3 & 2 \\
\hline Lepus californicus & 1 & 0 & 0 & 0 & 0 & 45 & 0.8 & 2.4 & 92.5 & 0 & 2 & 2 \\
\hline Lepus townsendii & 1 & 0 & 0 & 0 & 0 & & 19.63 & 3.262 & 5.73 & 1 & 4 & 2 \\
\hline Lontra canadensis* & 0 & 1 & 0 & 0 & 0 & 42 & 15 & 8.4 & 0.28 & 2.5 & 2 & 3 \\
\hline Lynx canadensis & 1 & 0 & 0 & 0 & 0 & 9.7 & 155 & 10 & 0.06 & 1 & 2 & 2 \\
\hline Lynx rufus & 1 & 0 & 0 & 0 & 0 & 56 & 38.4 & 8.2 & 0.03 & 0 & 8 & 2 \\
\hline Marmosa canescens & 0 & 0 & 1 & 0 & 0 & & 0.002 & 0.725 & 128 & 0 & 2 & 5 \\
\hline Marmota flaviventris & 0 & 0 & 0 & 1 & 0 & 1.4 & 0.00575 & 4 & 8.5 & 2 & 5 & 4 \\
\hline Marmota monax & 0 & 0 & 0 & 1 & 0 & 0.7 & 0.03412 & 3.676 & 148 & 1 & 4 & 2 \\
\hline Marmota vancouverensis & 0 & 0 & 0 & 1 & 0 & & 0.00575 & 4 & 0.5 & 3 & 1 & 2 \\
\hline Martes americana & 0 & 0 & 1 & 0 & 0 & 61 & 12.1 & 1 & 1.1 & 0 & 3 & 3 \\
\hline Martes pennanti & 0 & 0 & 1 & 0 & 0 & 22.6 & 25 & 3.5 & 0.10 & 0 & 4 & 3 \\
\hline Mephitis mephitis & 1 & 0 & 0 & 0 & 0 & 21.7 & 2.08 & 1.6 & 3.3 & 1 & 4 & 5 \\
\hline Microsorex boyi & 1 & 0 & 0 & 0 & 0 & & 0.003 & 0.0035 & 520 & 1 & 4 & 3 \\
\hline Microtus californicus & 1 & 0 & 0 & 0 & 0 & & 0.0055 & 0.062 & 5250 & 2 & 4 & 3 \\
\hline Microtus longicaudus & 1 & 0 & 0 & 0 & 0 & & 0.00882 & 0.047 & 2572 & 0 & 6 & 3 \\
\hline Microtus mexicanus & 1 & 0 & 0 & 0 & 0 & & 0.001 & 0.0385 & 7700 & 0 & 2 & 2 \\
\hline Microtus montanus & 1 & 0 & 0 & 0 & 0 & & 0.00015 & 0.059 & 31250 & 2 & 4 & 2 \\
\hline Microtus ochrogaster & 1 & 0 & 0 & 0 & 0 & 0.1 & 0.00165 & 0.042 & 5373 & 3 & 2 & 2 \\
\hline Microtus oeconomus & 1 & 0 & 0 & 0 & 0 & 1 & 0.0025 & 0.062 & 3750 & 1.5 & 3 & 2 \\
\hline Microtus oregoni & 0 & 0 & 0 & 1 & 0 & & 0.00068 & 0.021 & 2213 & 1.5 & 3 & 3 \\
\hline Microtus pennsylvanicus & 1 & 0 & 0 & 0 & 0 & 0.2 & 0.00179 & 0.0441 & 12202 & 1 & 4 & 2 \\
\hline Microtus pinetorum & 0 & 0 & 0 & 1 & 0 & & 0.0001 & 0.02345 & 730 & 2 & 3 & 3 \\
\hline Microtus richardsoni & 1 & 0 & 0 & 0 & 0 & & 0.00177 & 0.107 & 1041 & 0 & 2 & 2 \\
\hline Microtus townsendii & 1 & 0 & 0 & 0 & 0 & 0.1 & 0.00017 & 0.046 & 11400 & 2.5 & 2 & 2 \\
\hline Mustela erminea & 1 & 0 & 0 & 0 & 0 & 1 & 0.5875 & 0.061 & 1.32 & 0 & 5 & 1 \\
\hline
\end{tabular}


Appendix continued

\begin{tabular}{|c|c|c|c|c|c|c|c|c|c|c|c|c|}
\hline Species & Ter & Saq & Sar & Sfo & Gli & $\begin{array}{l}\text { Dispersal } \\
(\mathrm{km})\end{array}$ & $\begin{array}{l}\text { Home range } \\
\left(\mathrm{km}^{2}\right)\end{array}$ & $\begin{array}{l}\text { Body } \\
\text { size }(\mathrm{kg})\end{array}$ & $\begin{array}{l}\text { Population density } \\
\text { (individuals } \mathrm{km}^{-2} \text { ) }\end{array}$ & Sociality & Habitats & Diet \\
\hline Mustela frenata & 1 & 0 & 0 & 0 & 0 & & 1.16 & 0.205 & 0.22 & 0 & 12 & 1 \\
\hline Mustela nivalis & 1 & 0 & 0 & 0 & 0 & & 0.015 & 0.0375 & 10.5 & 0 & 8 & 1 \\
\hline Mustela vison & 1 & 1 & 0 & 0 & 0 & 45 & 3.8 & 0.792 & 4.2 & 0 & 1 & 3 \\
\hline Napaeozapus insignis & 1 & 0 & 0 & 0 & 0 & & 0.0175 & 0.0215 & 1304 & 1 & 3 & 4 \\
\hline Neotoma albigula & 1 & 0 & 0 & 0 & 0 & & 0.0486 & 0.18905 & 583 & 0 & 3 & 3 \\
\hline Neotoma cinerea & 1 & 0 & 0 & 0 & 0 & 2.2 & 0.055 & 0.36 & 400 & 1 & 4 & 4 \\
\hline Neotoma lepida & 1 & 0 & 0 & 0 & 0 & & 0.00053 & 0.137 & 365 & 0 & 3 & 2 \\
\hline Neotoma mexicana & 1 & 0 & 0 & 0 & 0 & & 0.055 & 0.33 & 400 & 0 & 4 & 4 \\
\hline Neurotrichus gibbsii & 1 & 0 & 0 & 0 & 0 & & 0.00633 & 0.00945 & 1350 & 4 & 4 & 2 \\
\hline Notiosorex crawfordi & 1 & 0 & 0 & 0 & 0 & & 0.00446 & 0.00592 & 2400 & 0 & 8 & 2 \\
\hline Ochotona princeps & 1 & 0 & 0 & 0 & 0 & 0.4 & 1.5655 & 0.1485 & 592 & 1 & 1 & 2 \\
\hline Odocoileus hemionus & 1 & 0 & 0 & 0 & 0 & 7.3 & 2.11 & 86 & 22 & 2 & 10 & 3 \\
\hline Odocoileus virginianus & 1 & 0 & 0 & 0 & 0 & 11.7 & 2.895 & 87 & 15 & 2 & 11 & 3 \\
\hline Ondatra zibethicus & 0 & 1 & 0 & 0 & 0 & 3.4 & 0.0028 & 1.1 & 4150 & 0 & 1 & 3 \\
\hline Oreamnos americana & 1 & 0 & 0 & 0 & 0 & & 18 & 90 & 0.7 & 2 & 3 & 3 \\
\hline Oryzomys nelsoni & 0 & 1 & 0 & 0 & 0 & & 0.003 & 0.069 & 1000 & 0 & 1 & 5 \\
\hline Oryzomys palustris & 0 & 1 & 0 & 0 & 0 & & 0.003 & 0.052 & 1350 & 0 & 2 & 5 \\
\hline Parascalops breweri & 0 & 0 & 0 & 0 & 0 & & 0.000003 & 0.04845 & 300 & 1 & 4 & 2 \\
\hline Peromyscus crinitus & 1 & 0 & 0 & 0 & 0 & & 0.0036 & 0.0165 & 1519 & 0 & 1 & 5 \\
\hline Peromyscus eremicus & 1 & 0 & 0 & 0 & 0 & & 0.003 & 0.02 & 32 & 0 & 5 & 4 \\
\hline Peromyscus keeni & 1 & 0 & 0 & 0 & 0 & & 0.003 & 0.02 & 500 & 1 & 3 & 4 \\
\hline Peromyscus leucopus & 0 & 0 & 1 & 0 & 0 & 1 & 0.0025 & 0.023 & 1250 & 1 & 9 & 4.5 \\
\hline Peromyscus madrensis & 0 & 0 & 1 & 0 & 0 & & 0.00057 & 0.0217 & 3002 & 1 & 4 & 3 \\
\hline Peromyscus maniculatus & 1 & 0 & 0 & 0 & 0 & 0.9 & 0.007 & 0.02 & 2200 & 1 & 10 & 5 \\
\hline Phenacomys intermedius & 1 & 0 & 0 & 0 & 0 & & 0.002 & 0.027 & 549 & 1 & 5 & 4 \\
\hline Procyon lotor & 1 & 0 & 0 & 0 & 0 & $265.5^{*}$ & 0.7 & 5.72 & 20 & 0.5 & 10 & 5 \\
\hline Rangifer tarandus & 1 & 0 & 0 & 0 & 0 & & 711 & 105 & 1.02 & 2 & 2 & 3 \\
\hline Reithrodontomys megalotis & 1 & 0 & 0 & 0 & 0 & & 0.0095 & 0.015 & 2530 & 1 & 7 & 2 \\
\hline Scalopus aquaticus & 0 & 0 & 0 & 0 & 0 & & 0.0109 & 0.1035 & 373 & 1 & 3 & 3 \\
\hline Sciurus aberti & 0 & 0 & 1 & 0 & 0 & & 0.06395 & 0.794 & 38.2 & 1 & 3 & 2 \\
\hline Sciurus carolinensis & 0 & 0 & 1 & 0 & 0 & & 0.018 & 0.533 & 500 & 1 & 4 & 2 \\
\hline Sciurus niger & 0 & 0 & 1 & 0 & 0 & 3.4 & 0.15598 & 0.9 & 289 & 1 & 4 & 2 \\
\hline Sorex cinereus & 1 & 0 & 0 & 0 & 0 & & 0.006 & 0.0036 & 948 & 0 & 4 & 2 \\
\hline Sorex fumeus & 1 & 0 & 0 & 0 & 0 & & 0.02353 & 0.0075 & 5967 & 0 & 2 & 2 \\
\hline Sorex longirostris & 1 & 0 & 0 & 0 & 0 & & 0.00637 & 0.0039 & 3700 & 0 & 4 & 3 \\
\hline Sorex lyelli & 1 & 0 & 0 & 0 & 0 & & 0.00709 & 0.0045 & 1500 & 0 & 2 & 2 \\
\hline Sorex merriami & 1 & 0 & 0 & 0 & 0 & & 0.00869 & 0.0059 & 1200 & 0 & 3 & 2 \\
\hline Sorex monticolus & 1 & 0 & 0 & 0 & 0 & & 0.03514 & 0.00666 & 1200 & 0 & 2 & 3 \\
\hline Sorex nanus & 1 & 0 & 0 & 0 & 0 & & 0.003 & 0.0025 & 500 & 0 & 4 & 2 \\
\hline Sorex ornatus & 1 & 0 & 0 & 0 & 0 & & 0.0004 & 0.00512 & 11100 & 2 & 2 & 2 \\
\hline Sorex palustris & 0 & 1 & 0 & 0 & 0 & & 0.0025 & 0.01385 & 180 & 0 & 1 & 2 \\
\hline Sorex tenellus & 1 & 0 & 0 & 0 & 0 & & 0.003 & 0.00375 & 1000 & 0 & 3 & 2 \\
\hline Sorex trowbridgii & 0 & 0 & 0 & 1 & 0 & & 0.024 & 0.0075 & 4784 & 0 & 3 & 4 \\
\hline Sorex vagrans & 1 & 0 & 0 & 0 & 0 & & 0.02234 & 0.007 & 1200 & 0 & 1 & 3 \\
\hline Spermophilus armatus & 0 & 0 & 0 & 1 & 0 & & 0.00303 & 0.425 & 8200 & 1 & 2 & 4 \\
\hline Spermophilus beecheyi & 0 & 0 & 0 & 1 & 0 & 1.3 & 0.005 & 0.7265 & 450 & 1 & 4 & 5 \\
\hline Spermophilus beldingi & 0 & 0 & 0 & 1 & 0 & 0.3 & 0.0005 & 0.35 & 15260 & 2 & 4 & 3 \\
\hline Spermophilus elegans & 0 & 0 & 0 & 1 & 0 & & 0.00055 & 0.3485 & 2340 & 2 & 2 & 2 \\
\hline Spermophilus lateralis & 0 & 0 & 0 & 1 & 0 & & 0.007 & 0.2625 & 2050 & 1 & 4 & 5 \\
\hline Spermophilus tereticaudus & 0 & 0 & 0 & 1 & 0 & & 0.003 & 0.125 & 530 & 2 & 2 & 4 \\
\hline Spermophilus variegatus & 0 & 0 & 0 & 1 & 0 & & 0.00295 & 0.69133 & 690 & 2 & 3 & 5 \\
\hline Spilogale gracilis & 1 & 0 & 0 & 0 & 0 & & 0.64 & 0.432 & 5 & 1 & 4 & 4 \\
\hline Sylvilagus bachmani & 1 & 0 & 0 & 0 & 0 & 0.4 & 0.0025 & 0.7 & 450 & 0 & 1 & 2 \\
\hline Sylvilagus floridanus & 1 & 0 & 0 & 0 & 0 & 2.3 & 0.0295 & 1.1892 & 954 & 0 & 6 & 2 \\
\hline Sylvilagus graysoni & 1 & 0 & 0 & 0 & 0 & & 0.02476 & 1.4725 & 75 & 0 & 3 & 2 \\
\hline Sylvilagus nuttallii & 1 & 0 & 0 & 0 & 0 & & 0.015 & 0.755 & 150 & 0 & 1 & 2 \\
\hline Sylvilagus transitionalis & 1 & 0 & 0 & 0 & 0 & & 0.0045 & 0.89 & 150 & 0 & 2 & 2 \\
\hline Synaptomys borealis & 1 & 0 & 0 & 0 & 0 & & 0.001 & 0.0305 & 1333 & 0 & 3 & 2 \\
\hline
\end{tabular}


Appendix continued

\begin{tabular}{|c|c|c|c|c|c|c|c|c|c|c|c|c|}
\hline Species & Ter & Saq & Sar & Sfo & Gli & $\begin{array}{l}\text { Dispersal } \\
(\mathrm{km})\end{array}$ & $\begin{array}{l}\text { Home range } \\
\left(\mathrm{km}^{2}\right)\end{array}$ & $\begin{array}{l}\text { Body } \\
\text { size }(\mathrm{kg})\end{array}$ & $\begin{array}{l}\text { Population density } \\
\text { (individuals } \mathrm{km}^{-2} \text { ) }\end{array}$ & Sociality & Habitats & Diet \\
\hline Synaptomys cooperi & 1 & 0 & 0 & 0 & 0 & & 0.001 & 0.035 & 1333 & 0 & 2 & 2 \\
\hline Tamias alpinus & 1 & 0 & 0 & 0 & 0 & & 0.0126 & 0.036 & 814 & 0 & 1 & 4 \\
\hline Tamias amoenus & 0 & 0 & 0 & 1 & 0 & & 0.022 & 0.051 & 125 & 0 & 3 & 5 \\
\hline Tamias canipes & 0 & 0 & 0 & 1 & 0 & & 0.016 & 0.07 & 650 & 0 & 3 & 5 \\
\hline Tamias cinereicollis & 0 & 0 & 1 & 0 & 0 & & 0.016 & 0.062 & 650 & 0 & 2 & 4 \\
\hline Tamias dorsalis & 1 & 0 & 0 & 0 & 0 & & 0.011 & 0.07 & 650 & 0 & 3 & 4 \\
\hline Tamias minimus & 0 & 0 & 0 & 1 & 0 & & 0.001 & 0.041 & 902.5 & 0 & 6 & 4 \\
\hline Tamias panamintinus & 1 & 0 & 0 & 0 & 0 & & 0.016 & 0.051 & 375 & 0 & 2 & 4 \\
\hline Tamias quadrimaculatus & 1 & 0 & 0 & 0 & 0 & & 0.0068 & 0.087 & 70 & 0 & 1 & 4 \\
\hline Tamias quadrivittatus & 0 & 0 & 0 & 1 & 0 & & 0.0197 & 0.067 & 130 & 0 & 2 & 4 \\
\hline Tamias speciosus & 0 & 0 & 0 & 1 & 0 & & 0.01385 & 0.0555 & 58.5 & 0 & 2 & 4 \\
\hline Tamias striatus & 0 & 0 & 0 & 1 & 0 & 0.9 & 0.0022 & 0.096 & 4000 & 0 & 1 & 4 \\
\hline Tamias townsendii & 0 & 0 & 1 & 0 & 0 & & 0.008 & 0.08 & 260 & 0 & 2 & 4 \\
\hline Tamias umbrinus & 0 & 0 & 0 & 1 & 0 & & 0.0195 & 0.0625 & 336 & 0 & 2 & 4 \\
\hline Tamiasciurus douglasii & 0 & 0 & 1 & 0 & 0 & & 0.00417 & 0.2265 & 23.7 & 0 & 2 & 5 \\
\hline Tamiasciurus hudsonicus & 0 & 0 & 1 & 0 & 0 & 0.6 & 0.00575 & 0.2 & 115 & 0 & 3 & 5 \\
\hline Thomomys bottae & 0 & 0 & 0 & 0 & 0 & 0.3 & 0.00038 & 0.15 & 860 & 0 & 9 & 2 \\
\hline Thomomys talpoides & 0 & 0 & 0 & 0 & 0 & 0.1 & 0.00014 & 0.11 & 32.7 & 0 & 5 & 2 \\
\hline Urocyon cinereoargenteus & 1 & 0 & 0 & 0 & 0 & 83.7 & 3.5 & 3.07 & 1.65 & 3 & 6 & 5 \\
\hline Urocyon littoralis & 1 & 0 & 0 & 0 & 0 & & 0.3 & 1.95 & 2.7 & 3 & 2 & 4 \\
\hline Ursus americanus & 1 & 0 & 0 & 0 & 0 & 28.8 & 45.5 & 77.27 & 3.17 & 0 & 7 & 4 \\
\hline Ursus arctos & 1 & 0 & 0 & 0 & 0 & 82 & 550 & 202.5 & 0.02 & 0 & 2 & 4 \\
\hline Vulpes vulpes & 1 & 0 & 0 & 0 & 0 & $302 *$ & 3.885 & 5.2 & 3 & 3 & 8 & 4 \\
\hline Zapus hudsonius & 1 & 0 & 0 & 0 & 0 & & 0.005 & 0.018 & 1713 & 0 & 3 & 4 \\
\hline Zapus princeps & 1 & 0 & 0 & 0 & 0 & & 0.0025 & 0.0275 & 256 & 0 & 3 & 3 \\
\hline Zapus trinotatus & 1 & 0 & 0 & 0 & 0 & & 0.0025 & 0.0275 & 305 & 0 & 4 & 4 \\
\hline
\end{tabular}

*An extreme value from the study of Sutherland et al. (2000); not used in formulating predictive relations between home range and dispersal distance in the present study.

Sources: Anderson and Wallmo (1984), Anthony et al. (1987), Armstrong \& Jones (1971, 1972), Baker (1983), Bandoli (1987), Barash (1989), Bartels \& Thompson (1993), Bear (1989), Bekoff (1977), Belk \& Smith (1991), Beneski \& Stinson (1987) Bergstrom (1988), Best (1996), Best \& Henry (1993), Best et al. (1992), Best et al. (1994a,b,c), Boonstra et al. (1987), Brown \& Heske (1990), Carraway \& Verts (1985, 1991a,b, 1993), Cervantes (1997), Chapman (1974, 1975a,b), Chapman \& Feldhamer (1982), Chapman et al. (1980), Churchfield (1990), Clark et al. (1987), Clawson et al. (1994a,b), Cole et al. (1998), Cornely \& Baker (1986), Cornely \& Verts (1988), Cunningham (1990), Currier (1983), Demarais \& Krausman (2000), Demarchi et al. (2000), Dolan \& Carter (1977), Douglas (1976), Doyle (1990), Eadie (1939), Eisenberg (1981), Ernest \& Mares (1987), Franzmann (1981), Frase \& Hoffmann (1980), French (1980), Fritzell \& Haroldson (1982), Fuller \& Sievert (2001), Galindo \& Krebs (1985), Gannon (1988), Gehring \& Swihart (2003), George (1989), George et al. (1986), Gilbert \& Krebs (1991), Gliwicz (1997), Goheen (2002), Gomez \& Anthony (1998), Gorman \& Stone (1980), Hall (1981), Hallett (1978), Hanski et al. (1991), Hart (1992), Hartman \& Krenz (1993), Hayes \& Harestad (2000), Hays \& Lidicker (2000), Hilton \& Best (1993), Hoffmann \& Owen (1980), Holling (1992), Ivan \& Swihart (2000), Jenkins \& Busher (1979), Jenkins \& Eshelman (1984), Johnson \& Armstrong (1987), King (1983, 1989), Kinlaw (1995), Kirkland \& Layne (1989), Koprowski (1994), Krebs \& Wingate (1985), Kurta (1995), Kwiecinski (1998), Lackey (1991a,b, 1996), Lackey et al. (1985), Lambin \& Krebs (1991, 1993), Lambin et al. (1992), Lapasha \& Powell (1994), Larivière \& Pasitschniak-Arts (1996), Larivière \& Walton (1997, 1998), Lim (1987), Linzey (1983), Long (1974), Lotze \& Anderson (1979), Ludwig (1984), MacCracken et al. (1985), McAllister \& Hoffmann (1988), McComb et al. (1993), McCorquodale et al. (1989), McManus (1974), Macêdo \& Mares (1988), Mech (1970, 1974), Merritt (1981), Moore \& Collins (1995), Mumford \& Whitaker (1982), Murie \& Michener (1984), Nagorsen (1987), Nash \& Seaman (1977), Negus et al. (1986), Novikov \& Moshkin (1998), Oaks et al. (1987), Olding \& Cockrum (1977), Owen \& Hoffmann (1983), Pasitschniak-Arts (1993), Pasitschniak-Arts \& Larivière (1995), Paulson (1988), Petersen \& Yates (1980), Pinter (1988), Poglayen-Neuwall \& Toweill (1988), Powell (1981, 1993), Redfield (1976), Reich (1981), Reid et al. (1994), Richens (1974), Rickart \& Heaney (2001), Rideout \& Hoffmann (1975), Ruggiero et al. (1994), Schweiger \& Boutin (1995), Schwilk \& Keeley (1998), Sheffield \& King (1994), Sheffield \& Thomas (1997), Sheperd \& Swihart (1995), Slough \& Mowat (1996), Smith (1991), Smith (1997), Smith \& Belk (1996), Smith \& Weston (1990), Smolen (1981), Smolen \& Keller (1987), Snyder (1982), Stalling (1990), Steele (1998), Stuart-Smith et al. (1997), Sullivan et al. (1997, 2001), Sutton (1992, 1993), Swihart (1992), Tamarin (1985), Thompson (1982), Ticul \& Arroyo-Cabrales (1990), Tumlison (1987), Veal \& Caire (1979), Verts \& Carraway (2002), Viitala (1994), Wade-Smith \& Verts (1982), Webster \& Jones (1982), WellsGosling \& Heaney (1984), Wheatley (1997), Whitaker (1972, 1974), Whitaker \& Wrigley (1972), Williams (1984), Willner et al. (1980), Wilson \& Ruff (1999), Wolfe (1982), Woods (1973), Yates \& Schmidly (1978), Zegers (1984). 